\title{
Índice de caminabilidad para la ciudad de Bogotá
}

\author{
Walkability index for the city of Bogotá \\ Índice de caminabilidade para a cidade de Bogotá
}

\section{Julián Alberto Gutiérrez-López}

Universidad El Bosque Bogotá (Colombia)

Departamento Administrativo de la Defensoría del Espacio Público, Bogotá (Colombia)

Grupo de Estudios sobre Espacio Público de la Defensoría del Espacio Público.

\section{Yolanda Beatriz Caballero-Pérez}

Universidad Nacional del Colombia, Bogotá (Colombia) Facultad de Ciencias

\section{Rubén Alejandro Escamilla-Triana}

Departamento Administrativo de la Defensoría del Espacio Público,

Bogotá (Colombia)

Subdirección de Registro Inmobiliario

Grupo de Estudios sobre Espacio Público

Gutiérrez-López, J. A., Caballero-Pérez, Y. B. \& Escamilla-Triana, R. A. (2019). Índice de caminabilidad para la ciudad de Bogotá. Revista de Arquitectura (Bogotá), 2(I), 8-20. doi: http://dx.doi.org/10.14718/RevArq.2019.21.I.I884

\section{(C) (P) $\$$ BY}

\author{
ulián Alberto Gutiérrez-López \\ Economista, Escuela Colombiana de Ingeniería Julio Garavito, Bo- \\ gotá (Colombia). \\ Magíster en Ciencias Económicas, Universidad Santo Tomás, Bogotá \\ (Colombia). \\ (D) http://orcid.org/0000-000 I-5296-0853 \\ julkeled@hotmail.com \\ Yolanda Beatriz Caballero-Pérez \\ Ingeniera Catastral y Geodesta, Universidad Distrital Francisco José \\ de Caldas, Bogotá (Colombia). \\ Especialista en Sistemas de Información Geográfica, Universidad \\ Distrital Francisco José de Caldas, Bogotá (Colombia). \\ Magíster en Estadística, Universidad Nacional de Colombia, Bogotá \\ (Colombia). \\ (D) htttp://orcid.org/0000-0002-50|8-426| \\ ybcaballerop@unal.edu.co \\ Rubén Alejandro Escamilla-Triana \\ Ingeniero Catastral y Geodesta, Universidad Distrital Francisco José \\ de Caldas. Bogotá (Colombia). \\ Especialista en Derecho Urbano, Universidad de los Andes. \\ (D) http://orcid.org/0000-0002-4750-3727 \\ rescamilla@dadep.gov.co
}

\section{Resumen}

La movilidad peatonal es un aspecto recurrente en los discursos de la ciudad actual. Se espera que en las ciudades se generen espacios urbanos que fomenten la caminabilidad y, de esta manera, se promueva la reducción de la movilidad vehicular y la recuperación de la calidad ambiental, a fin de mejorar la calidad de vida de los ciudadanos. De esta manera, es necesario evaluar en términos cuantitativos las diferentes condiciones que permitan tener desplazamientos a pie, y con ello servir de base para la implementación de políticas de movilidad y espacio público que aporten a la generación de entornos más amigables. Para el caso de Bogotá se plantea la construcción y medición del índice de caminabilidad basado en cinco componentes: calidad ambiental, densidad, confort, proximidad y entropía aplicados en las Unidades de Planeamiento Zonal (UPZ), mediante el análisis de bases de datos espaciales y herramientas de sistemas de información geográfica (SIG). Se construye el índice entendiendo que es un indicador relativo de qué tan bien está el entorno construido en diferentes áreas para caminar, y qué condiciones de entorno propician dicho comportamiento. Se logra diagnosticar cuáles son los grados de caminabilidad por cada UPZ, y se distinguen diversas condiciones en los sectores analizados.

Palabras clave: calidad de vida; espacio público; espacio urbano; indicadores urbanos; modelo de ciudad compacta; urbanismo.

\section{Abstract}

Pedestrian mobility has been a recurrent aspect in discourses on the contemporary city. It is expected that cities generate urban spaces that encourage walkability, promoting thus the reduction of vehicular mobility and the recovery of environmental quality, seeking to improve the quality of life of citizens. For this reason, it is necessary to quantitatively evaluate different conditions that allow citizens to have displacements on foot, and to use this as a basis for the implementation of mobility and public space policies that allow generating more pedestrian-friendly environments. In the case of Bogotá and its administrative divisions, the paper proposes the construction and measurement of a walkability index based on five components (environmental quality, density, comfort, proximity, and entropy) at the level of Zonal Planning Units (UPZ), through the analysis of spatial databases and Geographic Information System tools. This index is a relative indicator of how well the environment is constructed in different areas with respect to walking and what environmental conditions favor such behavior. It helps to diagnose the degree of walkability for each UPZ, as well as to distinguish diverse conditions in the analyzed areas.

Keywords: quality of life; public space; urban space; urban indicators; compact city model; urban planning.

\section{Resumo}

A mobilidade de pedestres é um aspecto recorrente nos discursos da cidade atual. Espera-se que, nas cidades, sejam gerados espaços urbanos que fomentem a caminhabilidade e, dessa maneira, seja promovida a redução da mobilidade veicular e a recuperação da qualidade ambiental a fim de melhorar a qualidade de vida dos cidadãos. Assim, é necessário avaliar, em termos quantitativos, as diferentes condições que permitem ter deslocamentos a pé e, com isso, servir de base para implantar políticas de mobilidade e espaço público que contribuam para gerar ambientes mais amigáveis. Para o caso de Bogotá, Colômbia, são propostas a construção e a mediação do índice de caminhabilidade baseado em cinco componentes: qualidade ambiental, densidade, conforto, proximidade e entropia aplicados nas Unidades de Planejamento Zonal (UPZ), mediante a análise de bases de dados espaciais e ferramentas de sistemas de informação geográfica (SIG). Foi construído o índice entendendo que é um indicador relativo de quão bem está o ambiente construído em diferentes áreas para caminhar e quais condições de entorno propiciam esse comportamento. Pode-se diagnosticar quais são os graus de caminhabilidade por cada UPZ e foram diferenciadas as condições nos setores analisados.

Palavras-chave: qualidade de vida; espaço público; espaço urbano; indicadores urbanos; modelo de cidade compacta; urbanismo. 


\section{Introducción}

El presente artículo se basa en el proyecto de investigación titulado "Índice de caminabilidad y precios del suelo" adelantado por el Grupo de Estudios sobre Espacio Público de la Defensoría del Espacio Público de Bogotá. Dicha investigación parte de la necesidad de reevaluar el planteamiento que tiene la ciudad hacia el peatón, reconociendo que caminar es la base de la pirámide de movilidad y como tal debe ser privilegiada ante las demás formas de transporte.

Partiendo de los principios de eficiencia y focalización del gasto público es indispensable diseñar metodologías que respondan el interrogante: ¿cuáles son las UPZ que presentan mejores y peores condiciones de caminabilidad? En este orden de ideas, se diseña un índice multidimensional, en cinco componentes, los cuales son calidad ambiental, densidad, confort, proximidad y entropía.

Para el desarrollo y el entendimiento del índice de caminabilidad es importante indagar qué significa este concepto, teniendo en cuenta que este adopta diferentes definiciones dependiendo de los escenarios en los que se aborde. Es por eso que en este trabajo se entenderá la caminabilidad basados en la definición de Leslie et al. (2007), citado por Fontan (2012), así:

\section{La "caminabilidad" de una comunidad puede ser definida como la medida en que las características del entorno construido y el uso del suelo pueden o no ser propicias para movimientos de a pie para los residentes de una determinada zona, ya sea para desarrollar actividades de ocio, ejercicio o la recreación, o para acceder a los servicios, viajar o trabajar (p. 8).}

La caminabilidad es un componente primordial en el diseño de los espacios urbanos, pues la viabilidad de esta constituye una alternativa fundamental a los problemas de movilidad de las ciudades, y una alternativa ambiental a los problemas de morbilidad, es por ello que un sinnúmero de autores han abordado el tema desde diferentes enfoques. Uno de estos es el enfoque de la salud, entre los autores de esta óptica encontramos a Zhu (2008), el cual analiza los diferentes componentes que debe tener un espacio, a fin de incentivar el hábito de caminar con el objetivo de prevenir enfermedades crónicas. Entre estos componentes el autor analiza la importancia de la seguridad a nivel de barrio y de la calle, y resalta el papel fundamental de esta en la toma de decisiones de los individuos al momento de realizar actividades al aire libre; dicho estudio fue desarrollado en la ciudad de Austin (Texas).

Por la misma línea, Rundle et al. (2009) y Rosenberg et al. (2009), en la ciudad de Nueva York, analizaron las características socioeconómicas y de entorno tales como: instalaciones recreo-deportivas, población, percepción y datos de seguridad, estética, continuidad y conectividad de las calles, y las contrastaron con el índice de masa corporal (IMC) de los habitantes. En el caso de Rundle et al. (2009), al igual que con la decisión de realizar actividad física en el caso de Rosenberg et al. (2009), en la ciudad de Nueva Jersey se encuentran estudios interesantes como los de Greenberg y Renne (2005), los cuales analizan la caminabilidad, la inactividad física y la morbilidad, recurriendo al apoyo de la ciudadanía con el fin de realizar una restructuración urbana que contara con la participación ciudadana. Todos los trabajos mencionados usan una metodología similar, que consiste en la recolección primaria de datos, junto con análisis de sectorización en términos de observación y percepción (seguridad, arbolado, mezclas de usos, etc.), analizados mediante herramientas de SIG.

Otros estudios se han enfocado en determinar los factores fundamentales que configuran la caminabilidad de las personas por las diferentes zonas de la ciudad. Dichos estudios serán fundamentales para este trabajo puesto que, dentro del mismo, no se plantea la recolección primaria de datos, la Tabla 1 muestra una revisión de la selección de variables en la medición de la caminabilidad, según diferentes autores.

En relación con la generación de actividad económica se han desarrollado otros trabajos, ya sea bajo su influencia en el comercio o en los precios del suelo. En esta vía encontramos planteamientos como los desarrollados por Smart Growth America (2014),

\footnotetext{
... estos encuentran que ciudades caminables tienen un Producto Interno Bruto per cápita 38\% más alto que en aquellas que no lo son, atraen personas con mayor nivel educativo, debido a que son más equitativos socialmente gracias a menores costos de transporte y mayor acceso a diversas ofertas de trabajo compensan los mayor(es) costo(s) de las viviendas (Martínez, 2016, citado por Leinberger y Rodríguez, 2016).
}

Igualmente, el estudio Walk this Way: The Economic Promise of Walkable Places in Metropolitan Washington, D.C., del instituto Brookings concluye:

\begin{abstract}
Los lugares "caminables urbanos" poseen una economía mucha más activa que los "no caminables", los lugares o distritos caminables que se conectan entre sí tienen rentas y valores de vivienda más altos, los residentes de los lugares más caminables tienen menores costos de transporte, mayor acceso a la infraestructura de transporte, pero rentas más altas, los residentes de los lugares menos caminables tienen menores ingresos y niveles educativos que los residentes de las zonas más caminables (Leinberger y Alfonzo, 2012, p. 1)
\end{abstract}

En la ciudad de Bogotá, la caminabilidad adquiere relevancia en dos aspectos fundamentales. En términos de salud, promueve la actividad física y es una alternativa viable al transporte motorizado, que contribuye a disminuir la congestión vehicular y a la reducción de consumo de combustibles fósiles y las emisiones de gases de efecto invernadero (GEI). En el segundo aspecto, se 
Owen, Humpel y Leslie (2004) Adelaida (Australia)

Saelens, Sallis y Frank (2003)

Cincinnati (Estados Unidos)

Adelaida (Australia)

Humpel, Owen, Leslie, Marshall, Bauman y Sallis (2004)

Leslie, Saelens, Frank, Owen, Bauman, Coffee, y Hugo (2005)

Adelaida (Australia)

Condado de King, Washington (Estados Unidos)

Frank, Sallis, Conway, Chapman,

Saelens, \& Bachman (2006)

Australia

Rattan, Campese \& Eden (2012)

Halton, Ontario (Canadá)

Agampatia (2014)

Nueva York (Estados Unidos)
Conectividad

Mezcla de usos

Comercio puntual

Densidad de vivienda

Proximidad

Densidad de usos

Mezcla de usos

Conectividad

Estética

Tráfico

Comodidad de las instalaciones Acceso

Densidad de la vivienda

Conectividad

Usos del suelo

Zonificación

Superficie comercial

Mezcla de uso de la tierra

La conectividad de la calle

Densidad residencial

Proporciones de superficie de ventas

Acceso a espacios abiertos

Acceso a la playa

Estética del barrio

Tráfico, carreteras más transitadas

Aceras presentes

Distancia caminando a tiendas

Paradas de tránsito

Tiendas de comestibles

Lugares de comida

Tiendas de convivencia Escuelas

Densidad residencial

Índice de entropía

Conectividad

Proximidad

Variables ambientales

Densidad comercial
A Tabla 1. Referentes internacionales en la selección de variables para la medición de caminabilidad

Fuente: elaboración propia, 2017. configura en el estímulo a la actividad comercial tal como se estipula en el plan de desarrollo de la ciudad (2016):

En la ciudad de Bogotá se adelantarán acciones para la promoción de calles comerciales a cielo abierto, para mejorar el potencial de la estructura económica y comercial urbana de la ciudad, dotándola con proyectos orientados a mejorar las condiciones de competitividad mediante el mejoramiento del espacio público. Del mismo modo, las calles comerciales a cielo abierto, se constituyen en ejes de promoción turística y de conectividad económica y ambiental (Alcaldía Mayor de Bogotá, 2016, p. 179).

\section{Beneficios de los espacios caminables}

Actualmente, las ciudades han encontrado en la planificación urbana un reto interesante para la conformación de lo que llamamos ciudad, por tanto, debe tener elementos consustanciales como tierra, transporte, vivienda, espacio público, equipamientos y servicios públicos que la distingan de lo que históricamente se entendían por villas. Es por ello que mejorar el ambiente urbano ha tomado un papel importante en la comunidad internacional, ya que esta labor está encaminada a generar espacios en los cuales los individuos puedan realizar cotidianamente aspectos de convivencia, dado que esta configura demográfica, económica, social y políticamente la concepción de ciudad (Borja, 1998).

En la configuración de esa urbe, los espacios públicos son fundamentales dado que no solo repercuten en los aspectos mencionados, sino que son esenciales para la mejora en la calidad de vida de los habitantes (Fontan, 2012).

Una de las ventajas fundamentales de un territorio caminable es la facilidad que tienen los individuos de encontrar una amplia gama de bienes y servicios, sin incurrir en altos costos de transporte, lo que les permite ver la acción de caminar como un sustituto cercano y saludable a los desplazamientos motorizados.

En términos económicos, las ventajas de la caminabilidad están más allá del entendimiento de ciudad como un conjunto de factores de producción; en esta vía, el Premio Nobel de Economía, Robert Lucas (1988), plantea el siguiente interrogante, dado que el suelo es mucho más barato fuera de las grandes ciudades, ipor qué las personas o las 
empresas no se mudan y aprovechan los menores costos para aumentar sus beneficios? Dicho interrogante devela que, en términos de preferencias, tanto los individuos como las firmas desean u obtienen utilidad por las localizaciones con presencia de más personas o de aglomerados, en este sentido, dicha preferencia por este tipo de localizaciones implica que la caminabilidad repercute directamente en los valores de la propiedad. La Figura 1 muestra de manera simplificada los principales beneficios la caminabilidad en un entorno urbano; como se mostró, la preferencia por la caminabilidad genera externalidades económicas y sociales como son los menores costos de transporte, menor contaminación, mayores interacciones sociales, entre otras.

\section{Aspectos que hacen un espacio caminable}

Ciertas particularidades del entorno influyen en la decisión de las personas en sus diferentes patrones de viaje, lo que conlleva la decisión de caminar y por dónde hacerlo. Por ejemplo, en los barrios con una amplia presencia de comercio, de colegios y demás, las personas estarían dispuestas a ir de compras por artículos básicos o ir a llevar a sus hijos al colegio a pie en lugar de ir en un vehículo. Asimismo, barrios con niveles de densidad poblacional altos presentarán mayores niveles de dotaciones que incentiven el despla- zamiento hacia este tipo de sitios; lugares con un mayor número de paradas de transporte público, animarán a las personas a desplazarse a estos, al igual que barrios con senderos peatonales seguros y estéticamente agradables configurarán un aspecto importante en la caminabilidad.

Es por esto que, para analizar el impacto de las variables en la caminabilidad, es importante identificar aquellas que sean pertinentes, medibles y fáciles de comprender. En esta vía, la Secretaría de Planeamiento de Buenos Aires (Álvarez de Celis et al., 2014) desagrega las variables que considera pertinentes en la medición (Tabla 2). (v) Figura 1. Beneficios de la caminabilidad

Fuente: elaboración propia, 2017. CC BY-NC.

\begin{tabular}{|c|c|c|}
\hline \multicolumn{2}{|c|}{ Variables de caminabilidad } & Recomendaciones \\
\hline Mixtura de usos & Mixtura de uso & Comercio minorista, oficinas, institucional. Diversidad de viviendas. \\
\hline Atractores peatonales & $\begin{array}{l}\text { Accesibilidad / conveniencia } \\
\text { (proximidad a destinos) }\end{array}$ & $\begin{array}{l}\text { Los destinos más importantes ubicados en proximidad } \\
\text { entre sí y a sectores residenciales. } \\
\text { No más de } 400 \text { metros entre origen y destino. }\end{array}$ \\
\hline Densidad & Densidad & $\begin{array}{l}\text { Densidad edilicia combinada con una adecuada } \\
\text { cantidad de espacios verdes. } \\
\text { Alta densidad de empleo. }\end{array}$ \\
\hline Acceso a espacios verdes & $\begin{array}{l}\text { Presencia de parques, } \\
\text { plazas y espacios abiertos }\end{array}$ & $\begin{array}{l}\text { Espacios abiertos públicos a escala barrial. } \\
\text { Sendas peatonales y veredas conectadas con espacios abiertos. } \\
\text { Áreas recreacionales. }\end{array}$ \\
\hline \multirow[t]{2}{*}{ Confort peatonal } & Calidad estética & $\begin{array}{l}\text { Calidad arquitectónica edilicia. } \\
\text { Tratamiento paisajístico en torno a residencias, } \\
\text { áreas comerciales y espacios públicos. } \\
\text { Áreas peatonales bien iluminadas. }\end{array}$ \\
\hline & $\begin{array}{l}\text { Servicios e infraestructuras peatonales } \\
\text { (veredas, cruces peatonales, etc.) }\end{array}$ & $\begin{array}{l}\text { Veredas de } 3 \text { a } 5 \text { m de ancho como mínimo (zonas residenciales y } \\
\text { comerciales respectivamente). } \\
\text { La franja de área verde debe estar presente siempre que sea posible. } \\
\text { Cobertura debe abarcar al menos al } 80 \% \text { de las casas y calles. }\end{array}$ \\
\hline Calidad ambiental & Calidad ambiental & $\begin{array}{l}\text { Arbolado urbano. } \\
\text { Baja contaminación acústica. } \\
\text { Baja contaminación atmosférica. }\end{array}$ \\
\hline
\end{tabular}

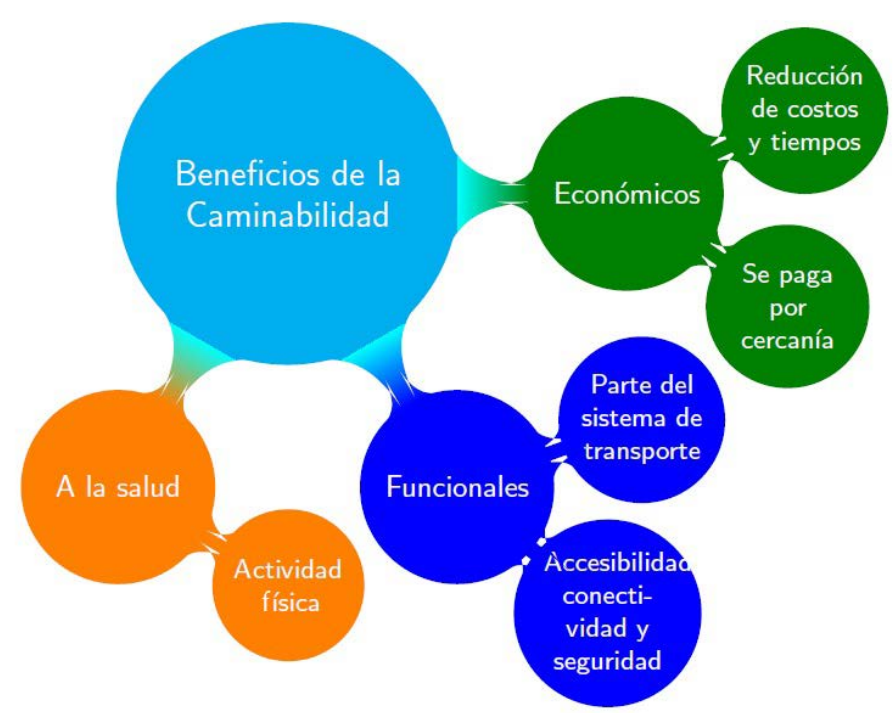

A Tabla 2. Características básicas de un entorno caminable Fuente: Álvarez de Celis et al. (2014, p. 18). 


\section{Metodología}

Para la construcción del indicador de caminabilidad en las diferentes Unidades de Planeamiento Zonal (UPZ) de la ciudad de Bogotá se tomaron como referencia las metodologías existentes para el cálculo de índices multivariados, considerando los referentes internacionales ya descritos, y se realizaron revisiones de la información disponible en la ciudad. Las variables fueron seleccionadas bajo los principios de pertinencia, funcionalidad, disponibilidad, confiabilidad y utilidad. Asimismo, se verificó el cumplimiento de criterios de calidad estadística, relevancia, credibilidad, accesibilidad, oportunidad y coherencia.

Las variables seleccionadas se agruparon en cinco subíndices (Tabla 3), la medición de cada variable y subíndice fue realizada por cada UPZ.

El cálculo de cada uno de los índices, y las variables que lo componen, se realizó mediante análisis de microdatos provenientes de bases de datos espaciales y alfanuméricas, por medio del uso de herramientas de sistemas de información geográfica (SIG) y paquetes estadísticos.

\section{Subíndice de calidad ambiental}

El subíndice de calidad ambiental agrupa variables que se relacionan con la calidad ambiental del entorno a nivel UPZ. Para este caso se consideraron las variables de densidad de arbolado urbano construido con la información suministrada por el Jardín Botánico José Celestino Mutis' ${ }^{1}$, el área de parque dentro de la UPZ construida con la información suministrada por el Departamento Administrativo de la Defensoría del Espacio Público ${ }^{2}$ y el Instituto Distrital de Recreación y Deporte ${ }^{3}$, y la variable de material particulado menor a 10 micras - PM10, construida con la información suministrada por la Secretaría Distrital de Ambiente ${ }^{4}$.

La calidad ambiental para este caso se calcula como la interacción de las tres variables que componen el subíndice, asignando el mismo peso a cada una, de modo que el subíndice de calidad ambiental para cada UPZ $\left(\mathrm{S}_{1}\right)$ se define como:

$$
s_{1}=\frac{A U_{E}+P+\left(1-P M_{E}\right)}{3}
$$

$S_{1}$ se encuentra en el rango $[0,1]$, valores cercanos a 1 representan mayor calidad ambiental y condiciones más propicias para caminar.

\section{Densidad de arbolado urbano}

El Jardín Botánico de Bogotá (Base de Datos Geográfica Corporativa, SDP, 2016) reportó un

1 Cálculos propios con información reportada a la Base de Datos Corporativa de la Secretaría Distrital de Planeación, 2016.

2 Cálculos propios con información del Sistema de Información Geográfica de la Defensoría del Espacio Público, 2016.

3 Cálculos propios con información reportada a la Base de Datos Corporativa de la Secretaría Distrital de Planeación, 2016. 4 Idem. total de 1'257.094 árboles urbanos. Para cada UPZ se define la variable aleatoria densidad de arbolado urbano (AU) como el número de árboles por hectárea:

$$
A U=\frac{\text { Número de árboles en la } U P Z}{\text { Área de terreno de la } U P Z(h a)}
$$

Definida la variable, esta se escala con el fin de que se distribuya dentro del rango $[0,1]$. La variable escalada $\mathrm{AU}_{\mathrm{e}}$ se calcula como:

$$
A U_{e}=\frac{A U-A U_{\min }}{A U_{\max }-A U_{\min }}
$$

\section{Proporción de área de parque por UPZ}

Tomando como fuente la capa de parques de la Defensoría del Espacio Público (2016), y a modo complementario la información reportada por el Instituto Distrital de Recreación y Deportes, se calcula la proporción de área de parque con respecto al área total de terreno para cada UPZ. De modo que la variable proporción de área de parque $(\mathrm{P})$ se define como:

$$
P=\frac{\text { Área total de parque en la } U P Z(m 2)}{\text { Área de terreno de la } U P Z(m 2)}
$$

\section{Material particulado inferior a $10 \mu$}

El valor de material particulado inferior a $10 \mu$ (PM10) indica la concentración de partículas menores a 10 micras en un metro cúbico de aire, se expresa en micras por metro cúbico y toma valores de cero en adelante. Para su estimación por UPZ se tomó como fuente información de la Secretaría Distrital de Ambiente, la variable se define como:

$$
P M=E[P M 10]=\sum_{K=1}^{n}\left[P M 10_{K}\right] \frac{A_{K}}{A}
$$

Donde $A$ es el área de la UPZ, y $A_{K}$ corresponde a la subdivisión de la UPZ en $n$ subregiones, cada una de ellas con un valor de $P M 1 O_{K}$.

Con el fin de que la variable tome valores entre cero y uno esta se escala de la siguiente manera:

$$
P M_{e}=\frac{P M-P M_{\min }}{P M_{\max }-P M_{\min }}
$$

\section{Subíndice de densidad}

Este subíndice agrupa variables relacionadas con densidad tanto poblacional como de ocupación y construcción. Se consideró la información de proyecciones de población a nivel de UPZ calculadas por la Secretaría Distrital de Planeación ${ }^{6}$. Para el caso de ocupación y construcción se toma como fuente la información proveniente de la Unidad Administrativa Especial de Catastro Distrital.

\section{Idem.}

6 Cálculos propios con proyecciones de población por UPZ y Base de Datos Corporativa de la Secretaría Distrital de Planeación, 2016. 


\section{Subíndice $\quad$ Variables que lo conforman}

Calidad ambiental

Arbolado urbano

Proporción de área de parque

Material particulado menor a 10 micras

Densidad

Densidad poblacional

Índice de ocupación

Índice de construcción
Proximidad

Distancia a equipamientos en un rango de $1 \mathrm{~km}$

\begin{tabular}{c} 
Confort \\
Entropía \\
Conectividad \\
$\begin{array}{c}\text { Pendiente } \\
\text { Dotación } \\
\end{array}$ \\
Mezcla de usos \\
Empleo \\
\hline
\end{tabular}

* Tabla 3. Subíndices que conforman el índice de caminabilidad calculado y las variables que lo componen

Fuente: elaboración propia, 2017.
El subíndice de densidad $S 2$ se calcula como la interacción de las tres variables que lo componen, se define como el promedio ponderado de las variables escaladas densidad poblacional (DPE), índice de construcción (ICE) y la variable índice de ocupación $(\mathrm{IO})$ se define como:

$$
S_{2}=\frac{\left.D P_{E}+\mathrm{IO}+I C_{E}\right)}{3}
$$

\section{Densidad poblacional}

La densidad poblacional se calcula en términos de habitantes por hectárea a nivel de UPZ y está definida como:

$$
D P=\frac{\text { Población } U P Z}{\text { Área de terreno de la } U P Z}
$$

Se realiza escalado de la variable DP para que tome valores dentro del rango $[0,1]$, de modo que la variable escalada DPE se calcula como:

$$
D P_{e}=\frac{D P-D P_{\min }}{D P_{\max }-D P_{\min }}
$$

\section{Índice de construcción}

Mediante técnicas de análisis espacial se calcula el área construida total ${ }^{7}$ para la UPZ (AC) como:

$$
A C=C *(N P+S+S S)
$$

Donde $c$ representa el área de terreno ocupada por la construcción, NP el número de pisos, y $S$ y SS representan el número de sótanos y semisótanos. Obtenida el área construida, se calcula el índice de construcción como el cociente de área construida de la UPZ sobre su área de terreno, se define como:

$$
I C=\frac{A C}{\text { Área de terreno de la } U P Z}
$$

Se realiza escalado de la variable IC para que tome valores dentro del rango $[0,1]$, de modo que la variable escalada $I C_{E}$ se calcula como:

$$
I C_{e}=\frac{I C-I C_{\min }}{I C_{\max }-I C_{\min }}
$$

\section{Índice de ocupación}

El área ocupada corresponde al área de terreno de una UPZ que se encuentra edificada ${ }^{8}$, el índice de ocupación se define como el cociente del área ocupada sobre el área de terreno de la UPZ (11), es una proporción y, por lo tanto, puede tomar valores en el rango $[0,1]$. El cálculo de área ocupada por UPZ se realizó mediante técnicas de análisis espacial.

$$
O=\frac{\text { Área ocupada } U P Z}{\text { Área de terreno } U P Z}
$$

\section{Subíndice de proximidad}

Este subíndice agrupa variables de proximidad, entendiendo esta como el número y la variedad de destinos dentro de una determinada área. Para su construcción se realizó un análisis de información reportada en la Base de Datos Corporativa de la Secretaría Distrital de Planeación (SDP), el Mapa de Referencia de la Unidad Administrativa Especial de Catastro Distrital y el Sistema de Información Geográfica de la Defensoría del Espacio Público.

El cálculo del subíndice contempla la localización de las siguientes variables en un radio de 1 $\mathrm{km}$ del contorno de cada manzana:

1. Estaciones de TransMilenio.

2. Paraderos del SITP.

3. Equipamientos de culto.

4. Equipamientos de cultura.

5. Equipamientos de deporte y recreación.

8 Cálculos propios con información del Mapa de Referencia de Bogotá de la Unidad Administrativa Especial de Catastro Distrital, 2016. 
6. Equipamientos educativos.

7. Equipamientos de educación superior.

8. Equipamientos de interacción social.

9. Equipamientos de recintos feriados.

10. Equipamientos de salud.

11. Equipamientos de sedes administrativas.

12. Equipamientos de seguridad.

13. Equipamientos de seguridad alimentaria.

14. Zonas verdes.

15. Parques.

Donde Dist ${ }_{i}$ corresponde a la distancia Euclidiana del contorno de la manzana a cada posible equipamiento en un radio de $1 \mathrm{~km}$, y corresponde a cada manzana contenida dentro de la UPZ.

$$
s 3=\frac{\sum_{k=1}^{n} \sum_{i=1}^{15}\left(1 \mathrm{Km}-\text { Dist }_{i}\right)}{N^{o} \text { de Manzanas }}
$$

Se realiza escalado del subíndice para que tome valores dentro del rango $[0,1]$, de modo que el índice escalado S3 E se calcula como:

$$
S 3_{e}=\frac{S 3-S 3_{\min }}{S 3_{\max }-S 3_{\min }}
$$

\section{Subíndice de confort}

Este subíndice de Confort agrupa variables que se relacionan con la amabilidad del entorno con el caminante. Se tuvo en cuenta conectividad, pendiente y disponibilidad de andén, estos datos fueron obtenidos mediante cálculos propios tomando como base información espacial del Instituto de Desarrollo Urbano.

El subíndice de confort $S_{4}$ se calcula como la interacción de las cuatro variables que lo componen, se define como el promedio ponderado de las variables disponibilidad de andén $(A N)$, dotación $(D O T)$, pendiente $(P E N)$ y conectividad $(C O N)$.

$$
s_{4}=\frac{\mathrm{AN}+\mathrm{DOT}+\mathrm{PEN}+\mathrm{CON}}{4}
$$

\section{Disponibilidad de andén}

Para evaluar la disponibilidad de andén (AN) en cada UPZ se tienen en cuenta la proporción de área de andén como indicador de abundancia y el ancho calculado de cada segmento como una medida de calidad. Debido a que la información espacial reportada no cuenta con datos consistentes y completos para el cálculo del ancho del andén, se realizó una estimación, asumiendo los andenes de la ciudad como un rectángulo de lado $h$ y largo $b$, donde el área del rectángulo está determinada por $A=b * h$ y el perímetro está determinado por $P=2 b+2 h$, por lo tanto, $b=(p-2 h) / 2$. Reemplazando el $b$ estimado en la fórmula de área, se obtiene:

$$
h=\frac{p}{4}-\sqrt{\frac{p^{2}}{16}-A}
$$

Por lo tanto, la disponibilidad de andén se define en función de la abundancia de este en el área de la UPZ y ancho de segmento; la ecuación muestra la metodología de cálculo de la variable AN.

$$
A N=\frac{\sum i \in U P Z A_{I} h_{i E}}{A}
$$

Donde $A_{i}$ corresponde al área del segmento de andén, $h_{i E}$ al ancho escalado del segmento $i$ de andén, y $A$ al área de la UPZ.

\section{Conectividad}

Para calcular la conectividad de cada UPZ (C) se tuvo en cuenta la densidad de nodos y el número de conexiones de cada nodo, definiendo nodo como una intersección vial. Para la zona urbana del Distrito Capital se identificó un total de 77.623 nodos, para cada nodo se calculó, mediante técnicas de análisis espacial, la cantidad de segmentos de vía que se conectan. A esta variable se le llamó conexión (Con), en la Figura 2 se muestran dos ejemplos de medición de la variable, a la izquierda un nodo en el que se conectan siete segmentos de vía (Con $=7$ ) y a la derecha un nodo que corresponde a una calle cerrada $($ Con $=1)$.

Cerca del $62 \%$ de los nodos conectan 3 segmentos viales y el $29 \%$ conectan 4 , solamente 4 nodos viales en el Distrito Capital conectan 7 segmentos viales, este es el valor máximo. Se puede resaltar la frecuencia de vías cerradas, que corresponden a cerca del $8 \%$ de los nodos.

Adicionalmente, se calcula la densidad de nodos viales por hectárea para cada UPZ (DN), una mayor densidad de intersecciones se relaciona también con mejores condiciones para caminar.

\section{Pendiente}

Para calcular la variable pendiente para cada UPZ (C) se tuvo en cuenta la pendiente de cada uno de los andenes y se ponderó mediante el área del andén sobre el total de andenes de la UPZ

$$
P E N=\frac{\sum \text { Pendiente del andén } * \text { área del andén }}{\text { Area del total de andenes de la UPZ }}
$$

Para el cálculo de cada andén se tomó como referente la cobertura de curvas del nivel de la Empresa de Acueducto y Alcantarillado de Bogotá, reportada en la Base de Datos Corporativa de la SDP, y con ello se determinó la cota más alta y la cota más baja, y calculando el largo del andén mediante la ecuación (19), se determinó la pendiente.

Se realiza escalado de la variable para que tome valores dentro del rango $[0,1]$, de modo que la variable $P E N_{\mathrm{e}}$ se calcula como:

$$
P E N_{e}=\frac{P E N-P E N_{\min }}{P E N_{\max }-P E N_{\min }}
$$



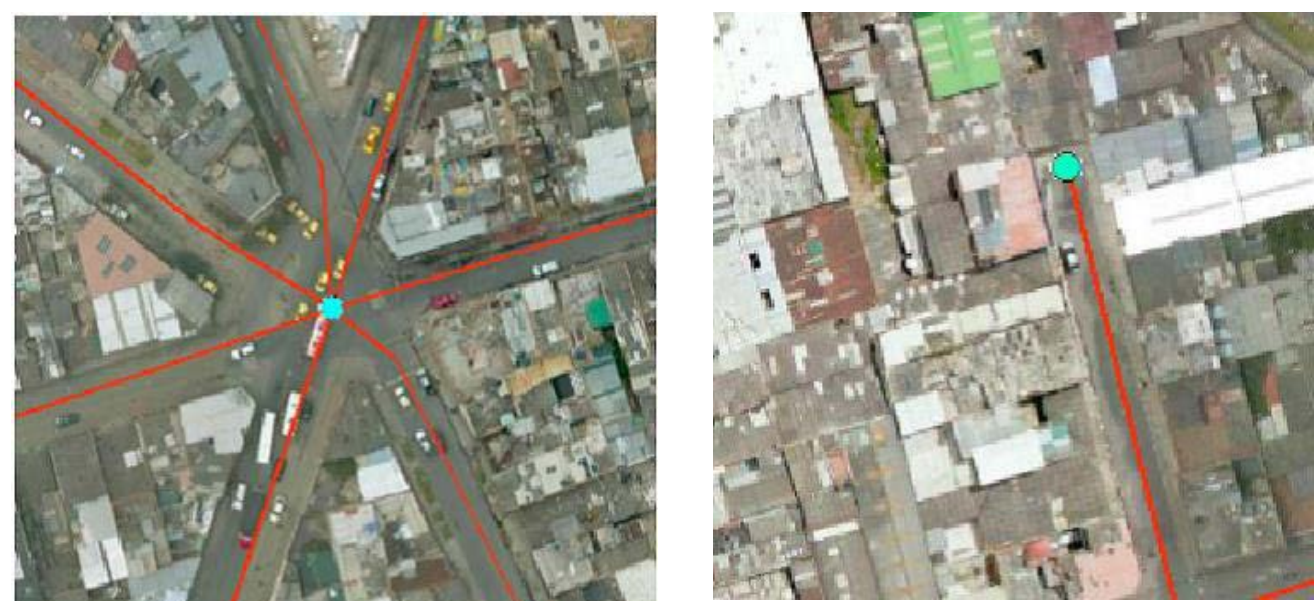

\& Figura 2. Ejemplos del cálculo de conectividad en el área urbana de Bogotá

Fuente: imagen base Ortofoto UAECD, 2014 y elaboración propia, 2017. CC BY-NC.

\section{Dotación}

Para calcular la variable de dotación se tomó la información espacial reportada por Codensa correspondiente a las luminarias de la ciudad, la información del Instituto de Desarrollo Urbano (IDU) con respecto a la cantidad de puentes peatonales por UPZ, la información del Departamento Administrativo de Defensoría del Espacio Público (DADEP) correspondiente al número de canecas de basura y sillas, y la información de la Secretaría de Movilidad con respecto a la cantidad de semáforos. Con dicha información se estimó la cantidad de cada atributo anteriormente mencionado, con respecto al área de la UPZ, de donde se obtuvo la variable dotación, como se muestra a continuación.

$$
\text { DOT }=\frac{\text { Pue }+ \text { lum }+c \& b+\text { sem }}{4}
$$

Donde pue corresponde a la cantidad de puentes con respecto al área en hectáreas de la UPZ, lum corresponde a la variable escalada de la cantidad de luminarias con respecto al área en hectáreas de la UPZ, c\&b corresponde a la variable escalada de la cantidad de cestas y bancas con respecto al área en hectáreas de la UPZ, y corresponde a la cantidad de semáforos con respecto al área en hectáreas de la UPZ.

\section{Subíndice de entropía}

El subíndice de entropía agrupa variables relacionadas con la diversidad de los usos del suelo, como datos del empleo; se consideró la información de personal ocupado a nivel de UPZ según cálculos de la Secretaría Distrital de Planeación, y la información de los usos del suelo tomando como fuente la información proveniente de la Unidad Administrativa Especial de Catastro Distrital.

El subíndice de entropía $S_{5}$ se calcula como la interacción de las dos variables que lo componen, se define como el promedio ponderado de las variables empleo (EM), y mezcla de usos $(M U)$

$$
s_{5}=\frac{\mathrm{EM}+\mathrm{MU}}{2}
$$

\section{Mezcla de usos}

Para calcular la mezcla de usos del suelo se utilizará la siguiente fórmula de entropía, con la

\begin{tabular}{|c|ccccccc|}
\hline Conexiones & $\mathbf{1}$ & $\mathbf{2}$ & $\mathbf{3}$ & $\mathbf{4}$ & $\mathbf{5}$ & $\mathbf{6}$ & $\mathbf{7}$ \\
\hline Frecuencia & 6012 & 3 & 48.247 & 22.509 & 740 & 108 & 4 \\
\hline$\%$ & 8 & 0 & 62 & 29 & 1 & 0 & 0 \\
\hline
\end{tabular}

(A) Tabla 4. Tabla de frecuencias de conexiones viales para el área urbana de la ciudad de Bogotá Fuente: elaboración propia, 2017.

finalidad de ver si hay homogeneidad o heterogeneidad en los atributos de los usos del suelo:

$$
\mathrm{MU}=\frac{-\sum_{k} p_{k} * \ln \left(p_{k}\right)}{\ln N}(22)
$$

Donde $k$ corresponde a la categoría del uso del suelo, $p$ corresponde al porcentaje de la superficie de cada uso específico del suelo, y $N$ corresponde al número de categorías del uso del suelo.

Los datos obtenidos se encuentran en una escala de 0 a 1, siendo 0 una UPZ homogénea, es decir, que los usos del suelo son del mismo tipo, no hay variedad, y 1 , que existen usos diferentes en la UPZ.

\section{Empleo}

Para calcular la variable empleo se tomaron como referentes datos de personal ocupado en el 2016, calculados por Secretaría Distrital de Planeación, reportados a nivel sector catastral, y se realiza la agregación a nivel UPZ; una vez determinado el empleo se divide en términos del área de la UPZ, así:

$$
E M=\frac{\text { Total del empleo de la UPZ }}{\text { Área de terreno UPZ }}
$$

\section{Resultados}

\section{$\mathrm{S}_{1}$ : resultados subíndice de calidad ambiental}

En promedio las UPZ tienen 0,217 en un rango de $[0,1]$ con una desviación estándar de 0,111 ; el valor más bajo es el obtenido por la UPZ Corabastos $(0,034)$, lo que significa que se trata de una UPZ, y el mayor valor -que además representa un dato atípico 0,6- obtenido para la UPZ Parque el Salitre. 


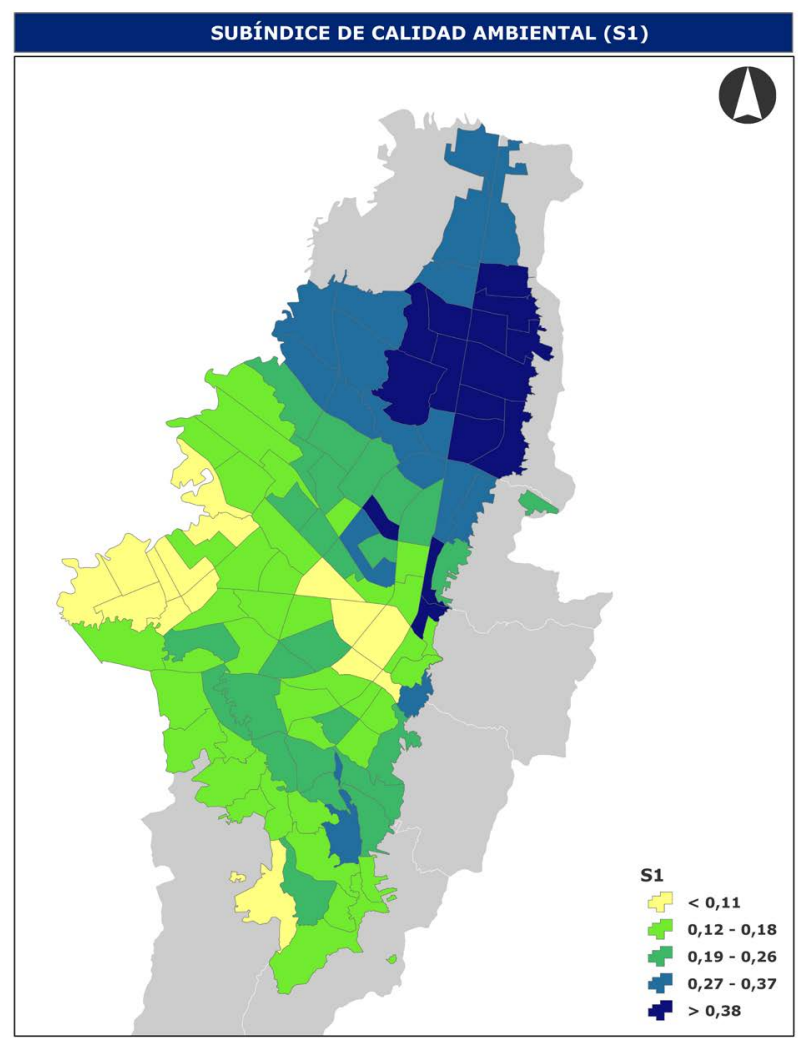

(A) Figura 3. Mapa de subíndice de calidad ambiental $\left(\mathrm{S}_{1}\right)$ por UPZ Fuente: elaboración propia, 2017. CC BY-NC.

(A) (A) Figura 4. Mapa subíndice de densidad $\left(\mathrm{S}_{2}\right)$ por UPZ

Fuente: elaboración propia, 2017. CC BY-NC.
En la Figura 3 se muestra la distribución espacial de los valores calculados de S1, los colores más oscuros representan mejor calidad ambiental, principalmente en las UPZ localizadas en la zona nororiental del área urbana del Distrito Capital, localidades de Usaquén y Suba; las UPZ 103-Parque el Salitre, 99-Sagrado Corazón y 91-Chapinero. En contraste, los valores más bajos, en colores claros, se encuentran agrupados en 9 UPZ al occidente de las localidades de Bosa y Kennedy, la UPZ 64-Monteblanco de la localidad Ciudad Bolívar, 111-Puente Aranda, 108-Zona Industrial, 102-La Sabana, 37-Santa Isabel y 95-Las Cruces. Se puede resaltar una agregación de UPZ con baja calidad ambiental en la zona central de la ciudad (Figura 3).

\section{$S_{2}$ : resultados subíndice de densidad}

El subíndice de densidad muestra en conjunto la densidad poblacional, el espacio construido y el espacio ocupado. En promedio, las UPZ tienen 0,412 en un rango de $[0,1]$, con una desviación estándar de 0,174 ; los valores más bajos representan aquellas UPZ con menores densidades, se destacan las UPZ 63-El Mochuelo $(0,024)$ y 60 -Parque Entre Nubes $(0,025)$; en contraste, valores cercanos a 1 representan mayor interacción entre densidad poblacional, alto índice de construcción y menor cantidad de espacio libre; se destaca la UPZ Patio Bonito que presenta un valor de 0,81, muy por encima de la media.

En la Figura 4 se muestra la distribución espacial de los valores calculados de $\mathrm{S}_{2}$, colores más oscuros muestran alta densidad compuesta por grandes cantidades de habitantes por hectárea, altos índices de construcción y menor área libre. Las UPZ que presentan los mayores valores $(\mathrm{S} 2>0,6)$ son, en su orden, 82-Patio Bonito

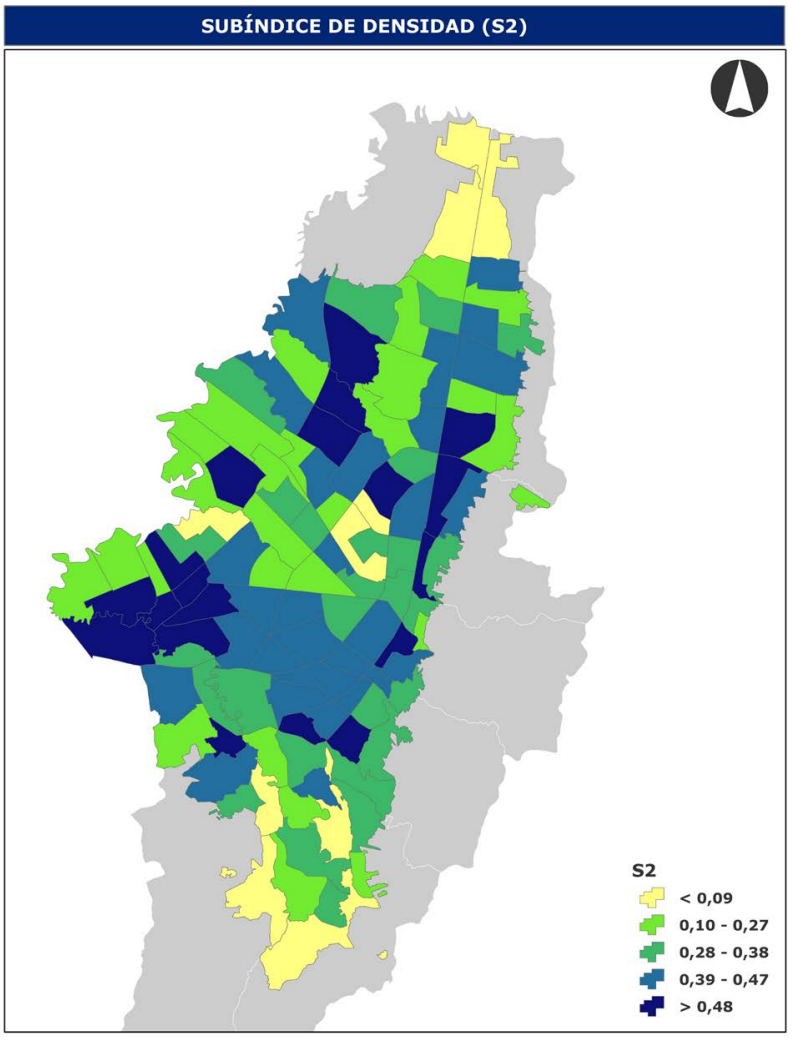

$(0,81)$, 66-San Francisco $(0,75), 84$-Bosa Occidental $(0,74)$, 81-Gran Britalia $(0,72)$, 28-El Rincón $(0,67)$, 80-Corabastos $(0,64), 93$-Las Nieves $(0,62), 34-20$ de Julio $(0,62)$ y 75 -Fontibón $(0,62)$ (Figura 4).

\section{$S_{3}$ : resultados subíndice de proximidad}

En la figura 5 se muestra la distribución espacial de los valores calculados de $S_{3}$. En promedio, las UPZ mostraron un valor de 0,6427 , con una desviación estándar de 0,14. Las UPZ en colores más oscuros muestran un mayor puntaje en términos de proximidad y diversidad de puntos atrayentes, las UPZ que presentan los mayores valores (S3 > 0,9) son, en su orden, 91-Sagrado Corazón, 92-La Macarena, 99-Chapinero, 105-Jardín Botánico, 107-Quinta Paredes y 94-La Candelaria. Estas cuentan con mayor acceso a equipamientos y servicios que propician el caminar (Figura 5).

\section{$\mathrm{S}_{4}$ : resultados subíndice de confort}

En promedio, las UPZ tienen 0,3547 en un rango de $[0,1]$, con una desviación estándar de 0,09, siendo el menor valor 0,0425 y el mayor 0,509.

En la figura 6 se muestra la distribución espacial de los valores calculados de $\mathrm{S}_{4}$; las UPZ en colores más oscuros muestran mayor nivel de confort compuesto por buena disponibilidad de andén, una baja pendiente, buena conectividad y una buena dotación; las UPZ que presentan los mayores valores $(\mathrm{S} 4>0,47)$ son, en su orden, 93-Las Nieves (0,509), 97-Chicó Lago $(0,4922), 37-S a n t a$ Isabel $(0,478)$ y 82 -Patio Bonito $(0,474)$ (Figura 6$)$.

\section{$S_{5}$ : resultados subíndice de entropía}

En promedio, las UPZ tienen 0,2614 en un rango de $[0,1]$, con una desviación estándar de 0,15 , donde el menor valor es 0,0613 , y el valor más alto es 0,7918. 


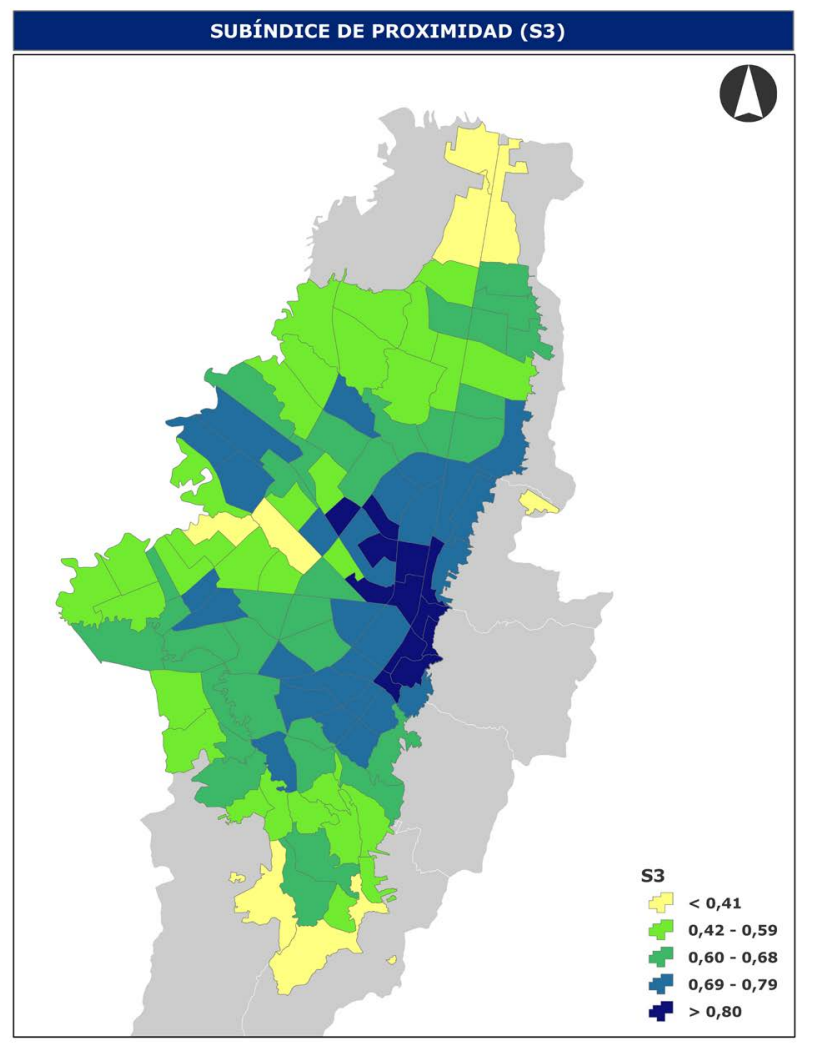

En la Figura 7 se muestra la distribución espacial de los valores calculados de $S_{5}$, las UPZ en colores más oscuros muestran diversidad en los usos del suelo y altos niveles de empleo. Las UPZ que presentan los mayores valores $(\mathrm{S} 5>0,6)$ son, en su orden, 91-Sagrado Corazón $(0,7918)$, 93-Las Nieves $(0,7176)$, 84-Bosa Occidental $(0,742926), 81-G r a n$ Britalia $(0,721292), 28$-El Rincón (0,666184), 99-Chapinero (0,6924), 101-Teusaquillo $(0,6465)$ y 97-Chicó Lago $(0,6348)$ (Figura 7$)$.

Para el cálculo del índice de caminabilidad se realizó la interacción de los cinco subíndices que lo componen, que se define como el promedio ponderado de los subíndices de calidad ambiental, densidad, proximidad, confort y entropía. Se obtuvieron los siguientes resultados:

En promedio, las UPZ tienen un índice de caminabilidad de 0,3626 , en un rango de $[0,1]$, con una desviación estándar de 0,08. La Figura 8 muestra el histograma de los valores obtenidos para el índice calculado por UPZ.

En la Figura 9 se muestra la distribución espacial de los valores calculados del índice de caminabilidad, las UPZ en colores más oscuros muestran los mayores puntajes en el índice, las 5 UPZ que presentan los mayores valores son, en su orden, 91-Sangrado Corazón $(0,6)$, 99-Chapinero $(0,582), 93$-Las Nieves $(0,551)$, 97-Chicó Lago $(0,634)$, y $101-T e u s a q u i l l o ~(0,4982)$. Altos valores de caminabilidad representan la interacción entre oferta, dada como buenas condiciones que ofrece la ciudad al peatón (i.e. calidad ambiental y confort), y demanda, entendida como la necesidad del ciudadano de transitar (i.e. entropía, densidad y proximidad). Los valores medios de caminabilidad pueden darse por la interacción de estos componentes, una unidad territorial puede tener valores medios de caminabilidad ya

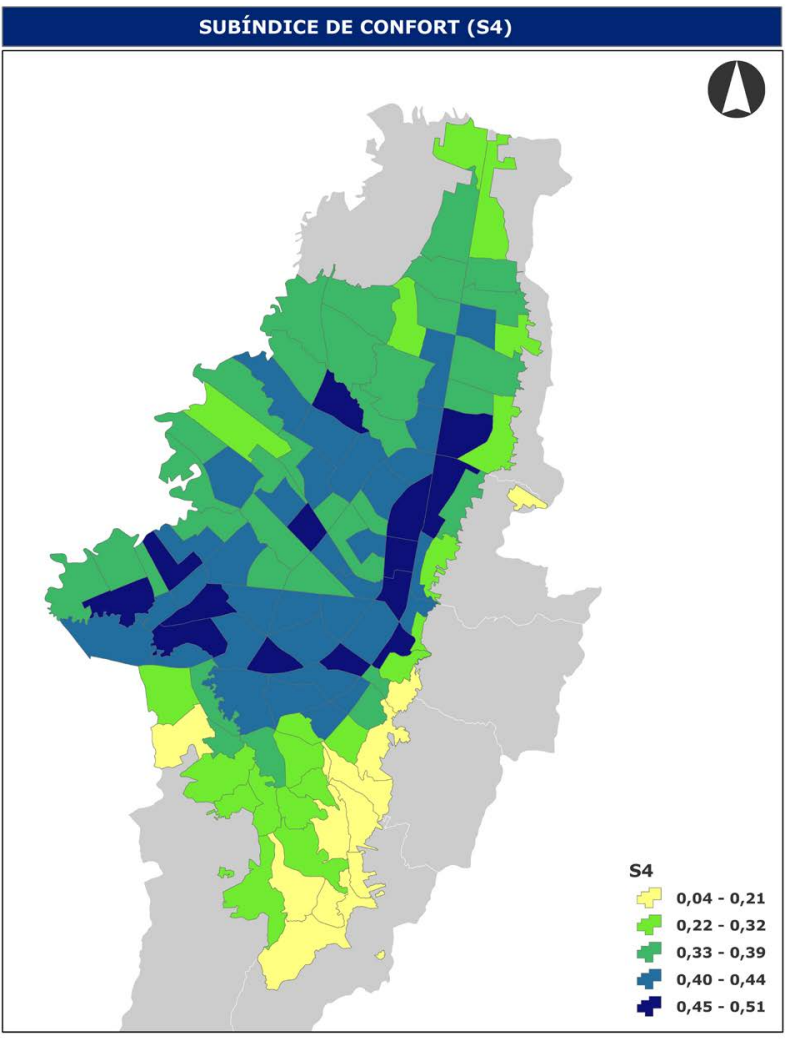

\&igura 5. Mapa subíndice de proximidad $\left(\mathrm{S}_{3}\right)$ por UPZ

Fuente: elaboración propia, 2017. CC BY-NC.

(8) Figura 6. Mapa subíndice de confort $\left(\mathrm{S}_{4}\right)$ por UPZ

Fuente: elaboración propia, 2017. CC BY-NC.

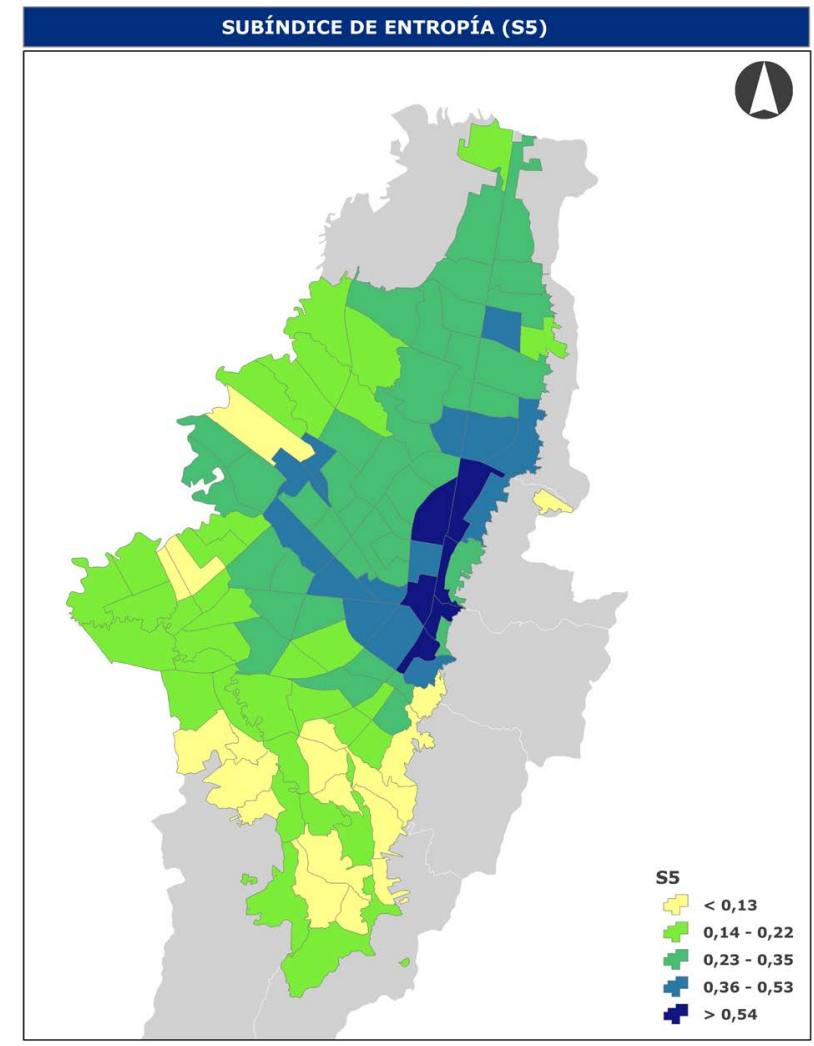

\& Figura 7. Mapa

Subíndice de entropía $\left(S_{5}\right)$ por UPZ

Fuente: elaboración propia, 2017. CC BY-NC sea por buenas condiciones urbanas, pero poca demanda peatonal, o bien, por alta demanda a pesar de malas condiciones urbanas.

Por otra parte, valores muy bajos de caminabilidad implican que la unidad territorial es deficiente tanto en las condiciones urbanas para el peatón como en la demanda de ciudadanos con necesidad de transitar en ella. La generación de políticas públicas debe ser dinámica en torno a enfocar sus esfuerzos en la mejora de las condiciones físicas que fomentan el caminar para el ciudadano, principalmente en las zonas que presentan mayor demanda de peatones. En la Figura 9 se muestran los resultados de la medición de caminabilidad, y sus componentes por subíndice para todas las UPZ, el valor más crítico en San Isidro-Patios 


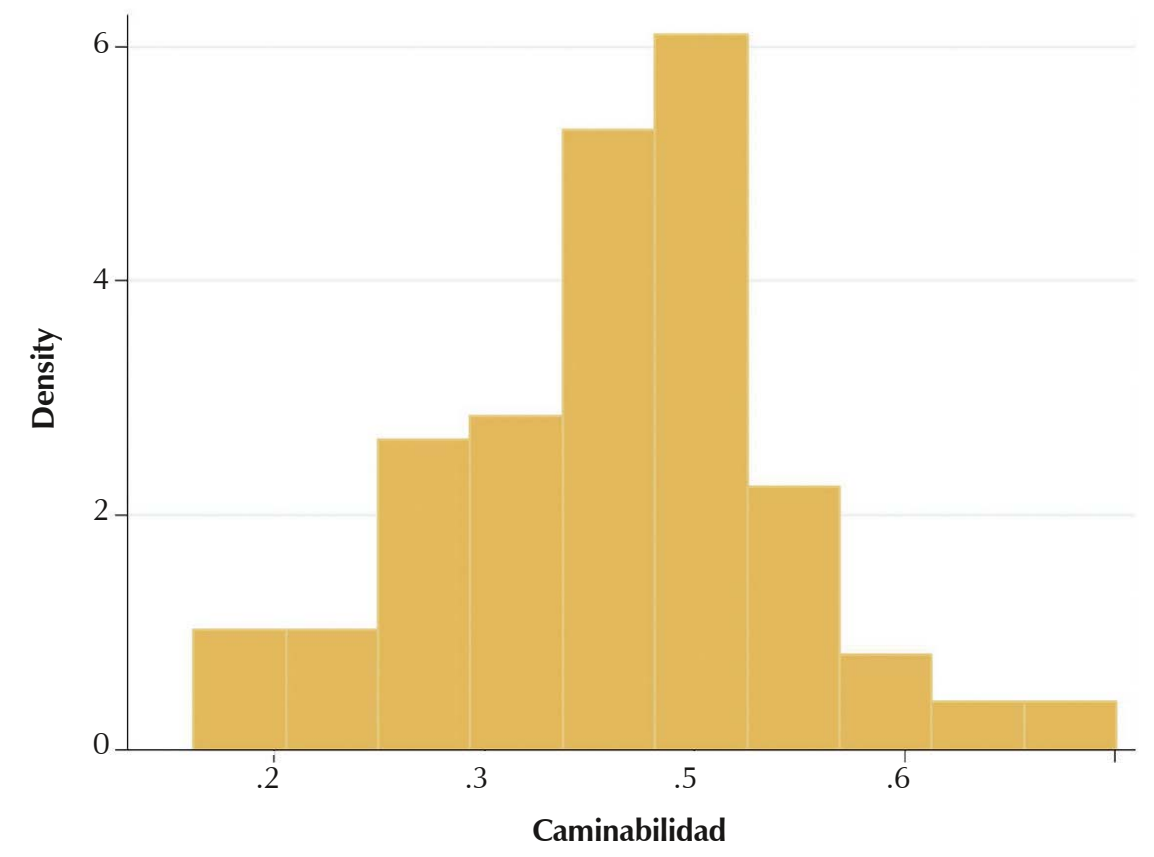

(A) Figura 8. Histograma del índice de caminabilidad calculado para las UPZ del Distrito Capital

Fuente: elaboración propia, 2017. CC BY-NC. condiciones urbanas para el peatón. muestra un territorio con buena calidad ambiental pero bajo confort, y aspectos deficientes en cuanto a proximidad y entropía,, lo que se traduce en poco acceso a servicios, sumado a malas

Otro caso de baja caminabilidad está representado en la UPZ Guaymaral, donde se presentan las peores condiciones de proximidad; sin embargo, su baja densidad se puede traducir en un territorio sin necesidad inminente de intervención pues la mayor parte del índice de caminabilidad lo aporta la buena calidad ambiental y aceptables condiciones de confort. En el otro extremo, las unidades territoriales con mayores índices de caminabilidad tienen más aporte en la demanda de los peatones para circular en ellas debido a las altas densidades y ofertas de bienes y servicios, sumado a regulares condiciones de confort y de calidad ambiental.

\section{Discusión}

El índice de caminabilidad propuesto es, en sí mismo, una medida de la interacción de los peatones con el entorno urbano; las cinco dimensiones que lo componen indican, en algunos casos, mayor oferta, lo que implica que el ciudadano tiene la necesidad de caminar por allí para satisfacerse de bienes o servicios a pesar de que posiblemente la infraestructura urbana no es la adecuada y no brinde condiciones para el peatón, es el caso de los subíndices de densidad, entropía y proximidad, la interacción entre estos tres subíndices indica UPZ con gran flujo de peatones. Por otra parte, los subíndices de confort y de calidad ambiental sí pretenden medir mejores condiciones urbanas para el caminante.

Los valores altos del índice propuesto denotan tanto grandes flujos peatonales como mejores condiciones.

Una ventaja es que cada una de las dimensiones es una medida útil para la toma de decisiones en varios aspectos de la planeación urbana. Por otro lado, la seguridad en términos de criminalidad en el espacio público es un aporte valioso que no fue tratado en el presente documento debido a la falta de disponibilidad de información, pero que debe ser integrado en la construcción del índice.

Mientras que los resultados del subíndice de calidad ambiental muestran que las menores condiciones se presentan en la zona nororiental de la ciudad, el subíndice de densidad muestra varias agregaciones de UPZ con altos valores en las localidades de Suba, Chapinero, Fontibón y Bosa. Los subíndices de proximidad y entropía señalan sus mejores valores en el centro de la ciudad, mientras que el subíndice de confort no presenta ninguna tendencia clara.

Los resultados finales del índice enmarcan una clara tendencia espacial en la zona centro de la ciudad en las zonas aledañas a la Avenida Caracas.

\section{Conclusiones}

Una de las más valiosas interacciones de los ciudadanos con su entorno urbano se da al caminar, pues es allí donde los habitantes se relacionan de manera directa con la ciudad. Caminar, además de ser una alternativa sostenible de movilidad, representa también una práctica importante en términos de salud pública. El índice de caminabilidad que se propone es, en sí mismo, una medida de la interacción de las personas con la ciudad, cada una de sus dimensiones mide el estado de un sector urbano en un componente específico, y brinda información acerca de las relaciones espaciales, sociales y económicas entre las personas y su entorno.

El índice propuesto en cinco dimensiones mide, por una parte, aquellas UPZ con mayor afluencia peatonal por encontrar mayores condiciones de densidad, mezcla de usos y oferta de bienes y servicios que obligan al peatón a circular, sin que ello implique mejores condiciones urbanas $y$, por otra parte, condiciones de confort y de calidad ambiental que pueden hacer más agradable la circulación del peatón.

La interacción de todas las dimensiones que concluyen en un valor cercano a 1 del índice propuesto se traduce en una UPZ caminable.

Sin embargo, algunas áreas urbanas son más caminables que otras, algunos valores medios del índice se pueden dar por buena mayor oferta y diversidad de bienes y servicios, pero pobres condiciones de infraestructura o calidad ambiental. Otras UPZ pueden presentar valores medios con buenas condiciones ambientales, de comodidad y características del entorno que facilitan la caminata, pero poca afluencia de peatones debido a la baja oferta de bienes y servicios.

El índice de caminabilidad se compone de cinco subíndices, cada uno de ellos mide de manera individual una dimensión del área urbana: 


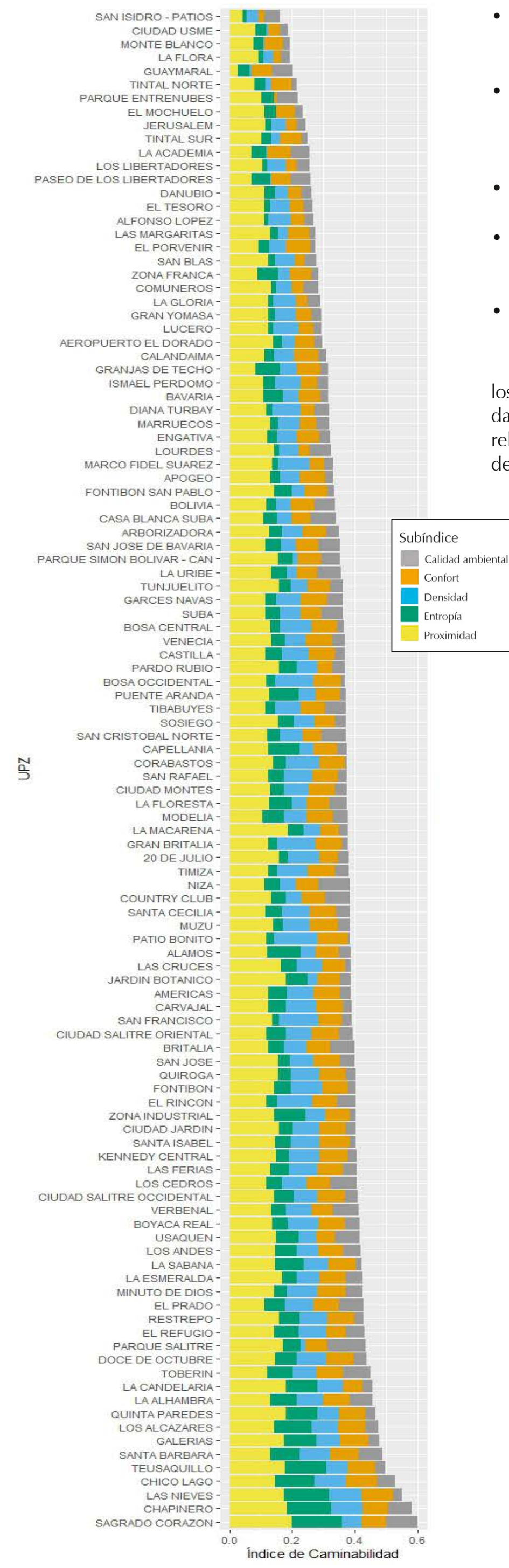

- Subíndice de calidad ambiental: agrupa variables que miden el estado ambiental de cada UPZ.

- Subíndice de densidad: es una medida global de densidad de la UPZ compuesta por densidad poblacional, índice de ocupación e índice de construcción.

- Subíndice de proximidad: mide la oferta y cercanía de bienes y servicios atractivos en la zona.

- Subíndice de confort: mide variables que brindan comodidad y que facilitan el desplazamiento a pie.

- Subíndice de entropía: es una medida de diversidad en usos del suelo.

Los resultados obtenidos tanto en cada uno de los subíndices como en el índice de caminabilidad brindan información valiosa para evaluar las relaciones de la ciudad; así, mientras el subíndice de calidad ambiental muestra resultados precarios

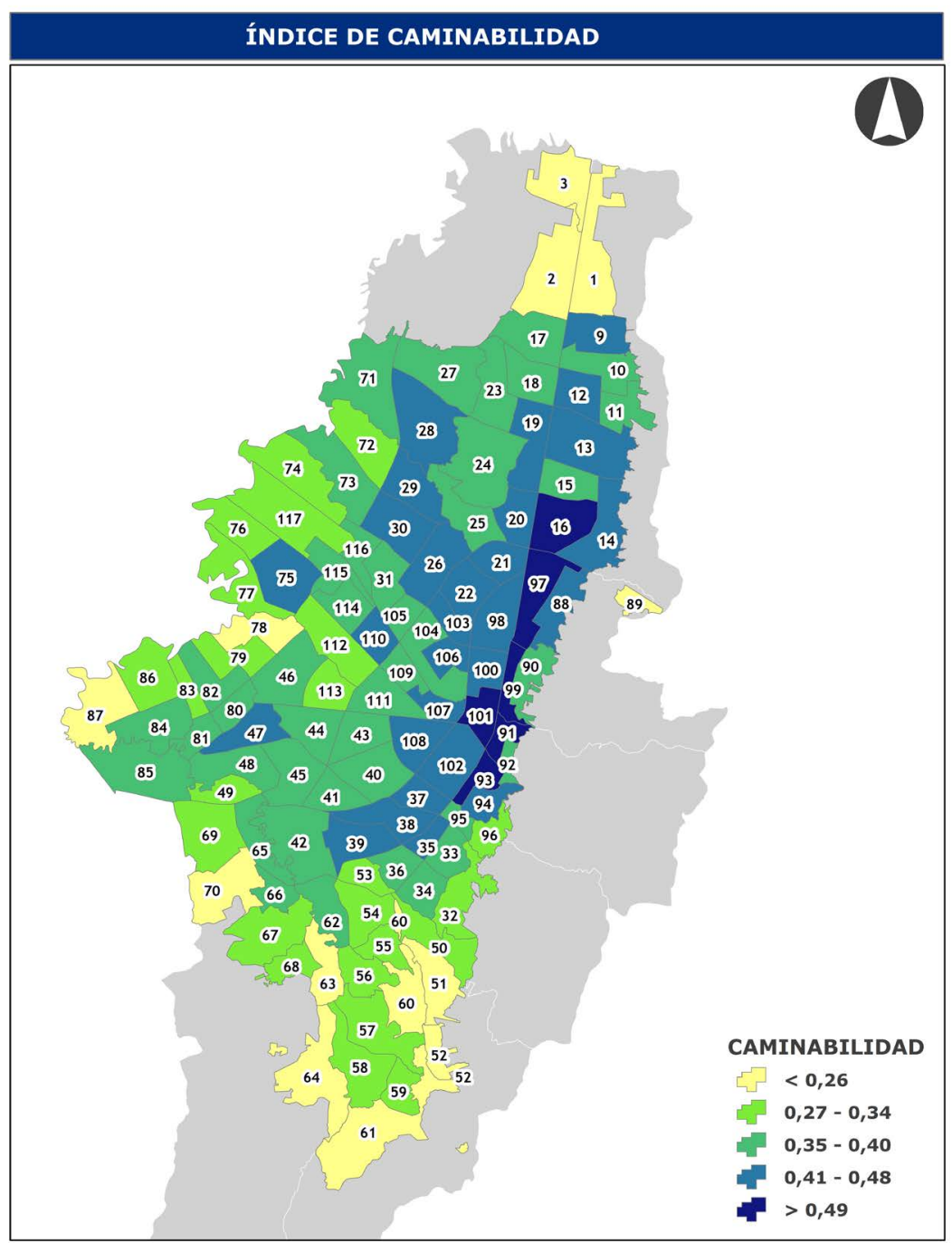

(A) Figura 10. Mapa Índice de caminabilidad por UPZ Fuente: elaboración propia, 2017. CC BY-NC.
\& Figura 9. Índice de caminabilidad por UPZ y su aporte por subíndice Fuente: elaboración propia, 2017. CC BY-NC 
en las UPZ más centrales de la ciudad, esto contrasta con los resultados de los subíndices de proximidad y entropía que muestran en esta zona la aglomeración de la oferta y diversidad de bienes y servicios. Por otra parte, la distribución espacial de los subíndices de confort y densidad es heterogénea. Resaltan agrupaciones de UPZ en áreas noroccidental, suroccidental y nororiental, con altas densidades tanto de edificaciones como de ocupación y habitantes.
El resultado del índice muestra una agrupación de UPZ en la zona central de la ciudad con los mayores índices de caminabilidad enmarcados en la zona aledaña a la Avenida Caracas, explicados en gran parte por mayor oferta, diversidad y densidad. En contraste con las UPZ con menor caminabilidad en zonas periféricas tanto en el extremo norte como sur de la capital, lo que se explica por menor oferta de bienes y servicios, infraestructura menos adecuada y menor densidad global.

\section{Referencias}

Agampatian, R. (2014). Using GIS to measure walkability: A case study in New York City (Master's of Science Thesis). School of Architecture and the Built Environment Royal Institute of Technology (KTH), Stockholm. Recuperado de http://urn.kb.se/ resolve?urn=urn:nbn:se:kth:diva-145011

Alcaldía Mayor de Bogotá (2016). Proyecto plan de desarrollo 2016-2020, Bogotá mejor para todos. Bogotá: Alcaldía Mayor de Bogotá. Recuperado de http://www.sdp.gov. $\mathrm{co} /$ portal/page/portal/PortalSDP/PlanDistritalDesarrollo/Documentos/20160429_proyecto_PDD.pdf

Álvarez de Celis, F., Álvarez Insúa, J., Eguía, S., Persico M. E., Belacin, S. y Trípoli F. (2014). Índice Sintético de Caminabilidad. Metodología. Indicadores de sustentabilidad urbana. Buenos Aires: Ministerio de Desarrollo Urbano. Secretaría de Planeamiento. Recuperado de: http://www.buenosaires.gob.ar/ sites/gcaba/files/caminabilidad_0.pdf

Borja, J. (1998, septiembre). Ciudadanía y espacio público. Ambiente y desarrollo. XIV(3), 13-22. Recuperado de http://www.pieb. org/espacios/archivos/doconline_ciudadania_y_espacio_publico.pdf

Defensoría del Espacio Público (2016). Reporte técnico de indicadores de espacio público. Bogotá: Observatorio del Espacio Público de Bogotá. Recuperado de http://observatorio.dadep.gov.co/reportes-tecnicos

Fontan Suárez, S. (2012). Índice de caminabilidad aplicado en la Almendra Central de Madrid (tesis de maestría). Universidad Complutense de Madrid, Madrid. Recuperado de https://eprints.ucm.es/20074/

Frank, L. D., Sallis, J. F., Conway, T. L., Chapman, J. E., Saelens, B. E. y Bachman, W (2006). Many pathways from land use to health: Associations between neighborhood walkability and active transportation, body mass index, and air quality. Journal of the American Planning Association, 72(1), 75-87. Doi: https://doi. org/10.1080/01944360608976725

Giles-Corti, B. y Donovan, R. J. (2002). Socioeconomic status differences in recreational physical activity levels and real and perceived access to a supportive physical environment. Preventive medicine, 35(6) 601-611. Doi: https://doi.org/10.1006/ pmed.2002.1115
Greenberg, M. R. y Renne, M. J. (2005). Where does walkability matter the most? An environmental justice interpretation of New Jersey data. Journal of urban health,82(1), 90-100. Doi: https://doi.org/10.1093/jurban/jti011

Humpel, N., Owen, N., Leslie, E., Marshall, A. L., Bauman, A. E. y Sallis, J. F. (2004). Associations of location and perceived environmental attributes with walking in neighborhoods. American Journal of Health Promotion,18(3), 239-242. Doi: https://doi.org/10.4278/08901171-18.3.239

Jardín Botánico (2016). Sistema de Información para la Gestión del Arbolado Urbano de Bogotá D.C. Bogotá: SIGAU. Recuperado de http://sigau.jbb.gov.co/SigauJBB/VisorPubli$\mathrm{Co} /$ VisorPublico

Leinberger, C. B. y Alfonzo, M. (2012, may). Walk this Way: The Economic Promise of Walkable Places in Metropolitan Washington, D.C. (Series: Walkable Urbanism). Washington, D.C.: Brookings. Recuperado de https:// www.brookings.edu/research/walk-thiswaythe-economic-promise-of-walkableplaces-in-metropolitan-washington-d-c/

Leinberger, C. B. y Rodriguez, M. (2016) Foot Traffic Ahead Ranking Walkable Urbanism in America's Largest Metros 2016. Washington D. C.: George Washington University. School of Business. Recuperado de https:// www.smartgrowthamerica.org/app/legacy/ documents/foot-traffic-ahead-2016.pdf

Leslie, E., Saelens, B., Frank, L., Owen, N., Bauman, A., Coffee, N. y Hugo, G. (2005). Residents' perceptions of walkability attributes in objectively different neighbourhoods: A pilot study. Health Place, 11(3), 227 36. Doi: https://doi.org/10.1016/j.healthplace.2004.05.005

Leslie, E., Coffee, N., Frank, L., Owen, N. Bauman, A. y Hugo, G. (2007). Walkability of local communities: Using geographic information systems to objetively asses relevant environmental attributtes. Health and Place, 13(1), 111-122. Doi: https://doi. org/10.1016/j.healthplace.2005.11.001

Lucas, R. E. (1988). En la mecánica del desarrollo económico. Diario de la economía monetaria, 22 (1), 3-42.

Martínez Gaete, C. (2016). El poder económico y social de las ciudades caminables. Plataforma Arquitectura. Recuperado de https:// www.plataformaarquitectura.cl/cl/793979/ el-poder-economico-y-social-de-las-ciudades-caminables

Owen, N., Humpel, N., Leslie, E., Bauman, A. y Sallis, J. F. (2004). Understanding environmental influences on walking: Review and research agenda. American Journal of Preventive Medicine, 27(1), 67 76. Doi: https:// doi.org/10.1016/j.amepre.2004.03.006

Rattan, A., Campese, A. y Eden, C. (2012, Winter). Modeling walkability. Automating analysis so it is easily repeated. ArcUser, 30-3. Recuperado de http://www.esri.com/news/ arcuser/0112/modeling-walkability.html

Rosenberg, D., Ding, D., Sallis, J. F., Kerr, J., Norman, G. J., Durant, N., Harrris, S. K. y Saelens, B. E. (2009). Neighborhood Environment Walkability Scale for Youth (NEWS-Y): Reliability and relationship with physical activity. Preventive medicine, 49(2-3), 213-218. Doi: https://doi.org/10.1016/j. ypmed.2009.07.011

Rundle, A., Neckerman, K. M., Freeman, L., Lovasi, G. S., Purciel, M., Quinn, J., Richards, C., Neelanjan, S. y Weiss, C. (2009, March). Neighborhood food environment and walkability predict obesity in New York City. Environmental health perspectives, 117(3), 442. Doi: https://doi.org/10.1289/ ehp. 11590

Saelens, B. E., Sallis, J. F. y Frank, L. D. (2003). Environmental correlates of walking and cycling: Findings from the transportation, urban design, and planning literatures. Annals of behavioral medicine, 25(2), 80-91. Doi: https://doi. org/10.1207/S15324796ABM2502_03

Smart Growth America (2014). Foot Traffic Ahead Report M+R Media Outreach Wrapup Report. Washington, DC: Smart Growth America. Improving lives by improving communities. Recuperado de http://www. chrisleinberger.com/docs/By CL/Foot\%20 Traffic\%20Ahead\%20Media\%20Summary. pdf

Zhu, W. (2008). Let's keep walking. Medicine \& Science in Sports \& Exercise. 40(7), S509-S511. Doi: https://doi.org/10.1249/MSS.0b013e3 1817c72af 


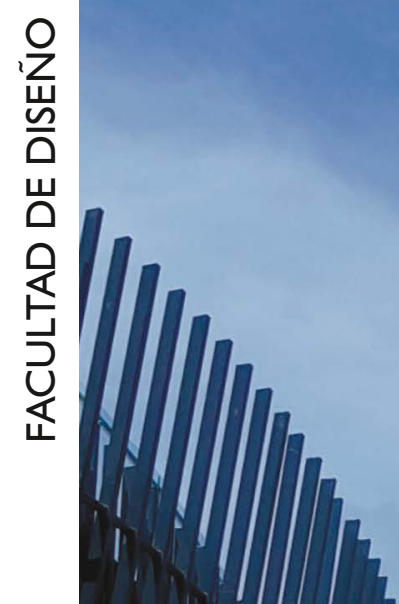

Vol.

\section{Nro. 1REVISTA DE ARQUITECTURA}
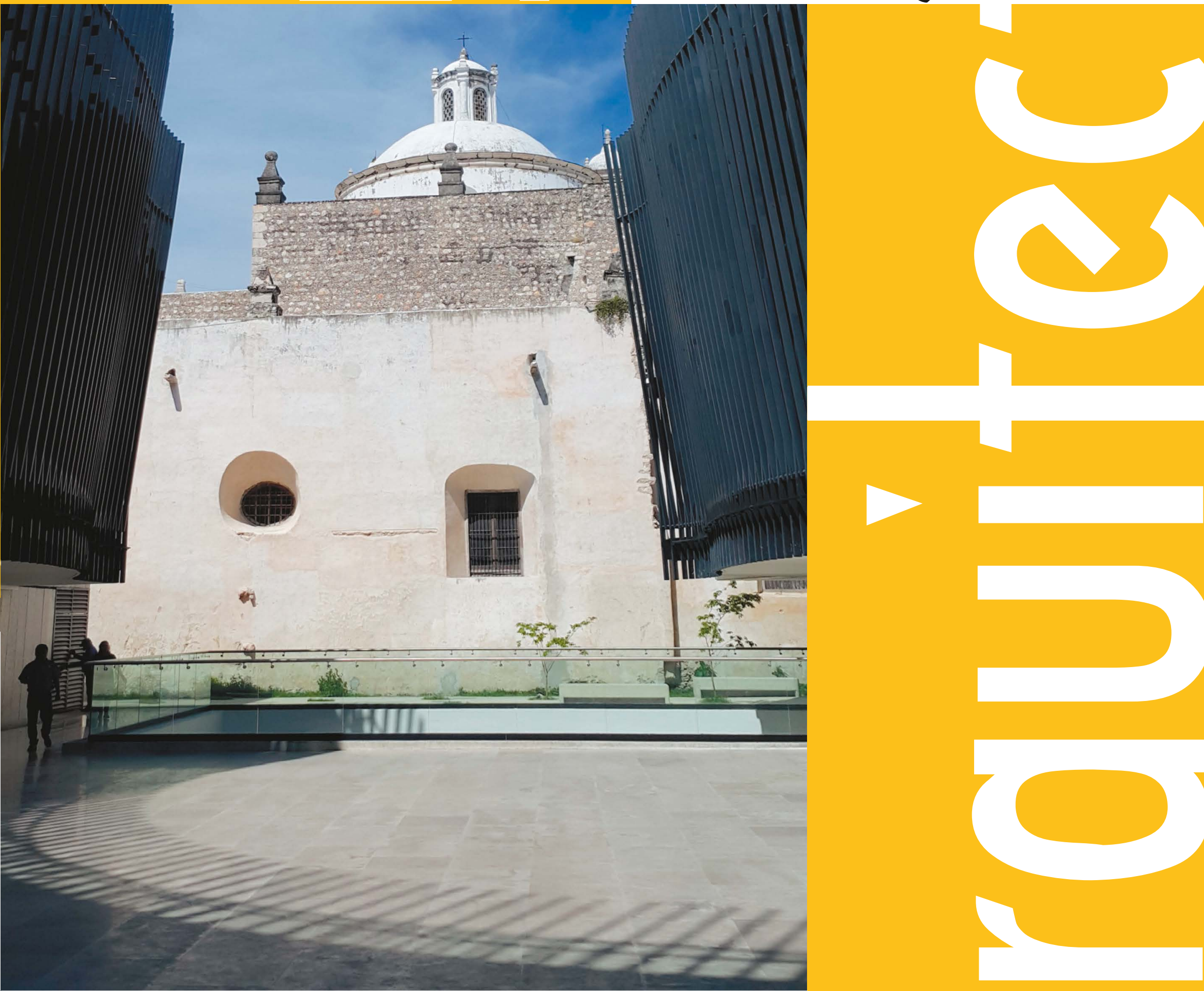
A) Portada: Palacio de la Música y Rectoria El J Júśs Tercera Orden. Mérida, Yucatán (México).

Fotografía: César Eligio-Triana (2018, septiembre) CC BY-NC

\section{(c) (1) ( $)$}

A Orientación editorial

\section{Enfoque y alcance}

La Revista de Arquitectura (Bogotá) ( (ISSN 1657-0308 Impresa y E-ISSN 2357-626X en línea) es una publicación seriada de acceso abierto, arbitrada mediante revisión por pares (doble ciego) e indexada, en donde se publican resultados de investigación originales e inéditos.

Está dirigida a la comunidad académica y profesional de las áreas afines a la disciplina. Es editada por la Facultad de Diseño y el Centro de Investigaciones (CIFAR) de la Universidad Católica de Colombia en Bogotá (Colombia).

La principal área científica a la que se adscribe la Revista de Arquitectura (Bogotá) según la OCDE es:

Gran área: 6. Humanidades

Área: 6.D. Arte

\section{Disciplina: 6D07. Arquitectura y Urbanismo}

También se publican artículos de las disciplinas como 2A02, Ingeniería arquitectónica; 5G03, Estudios urbanos (planificación y desarrollo); 6D07, Diseño.

Los objetivos de la Revista de Arquitectura (Bogotá) son:

- Promover la divulgación y difusión del conocimiento generado a nivel local, nacional e internacional

- Conformar un espacio para la construcción de comunidades académicas y la discusión en torno a las secciones definidas.

- Fomentar la diversidad institucional y geográfica de los autores que participan en la publicación.

- Potenciar la discusión de experiencias e intercambios científicos entre investigadores y profesionales.

- Contribuir a la visión integral de la arquitectura, por medio de la concurrencia y articulación de las secciones mediante la publicación de artículos de calidad.

- Publicar artículos originales e inéditos que han pasado por revisión de pares, para asegurar que se cumplen las normas éticas, de calidad, validez científica, editorial e investigativa.

- Fomentar la divulgación de las investigaciones y actividades desarrolladas en la Universidad Católica de Colombia.
Palabras clave de la Revista de Arquitectura (Bogotá): arquitectura, diseño, educación arquitectónica, proyecto y construcción, urbanismo.

Idiomas de publicación: español, inglés, portugués y francés. Título abreviado: Rev. Arquit.

\section{Titulo corto: RevArq}

\section{Políticas de sección}

La revista se estructura en tres secciones correspondientes a las líneas de investigación activas y aprobadas por la institución, y dos complementarias, que presentan dinámicas propias de la Facultad de Diseño y las publicaciones relacionadas con la disciplina.

Cultura y espacio urbano. En esta sección se publican los artículos que se refieren a fenómenos sociales en relación con el espacio urbano, atendiendo aspectos de la historia, el patrimonio cultural y físico, y la estructura formal de las ciudades y el territorio.

Proyecto arquitectónico y urbano. En esta sección se presentan artículos sobre el concepto de proyecto, entendido como elemento que define y orienta las condiciones proyectuales que devienen en los hechos arquitectónicos o urbanos, y la forma como estos se convierten en un proceso de investigación y nuevo de conocimiento. También se presentan proyectos que sean resultados de investigación, los cuales se validan por medio de la ejecución y transformación en obra construida del proceso investigativo. También se contempla la publicación de investigaciones relacionadas con la pedagogía y didáctica de la arquitectura, el urbanismo y el diseño.

Tecnología, medioambiente y sostenibilidad. En esta sección se presentan artículos acerca de sistemas estructurales, materiales y procesos constructivos, medioambiente y gestión, relacionados con los entornos social-cultural, ecológico y económico.

Desde la Facultad. En esta sección se publican artículos generados en la Facultad de Diseño, relacionados con las actividades de docencia, extensión, formación en investigación o internacionalización, las cuales son reflejo de la dinámica y de las actividades realizadas por docentes, estudiantes y egresados; esta sección no puede superar el $20 \%$ del contenido.

Textos. En esta sección se publican reseñas, traducciones y memorias de eventos relacionados con las publicaciones en Arquitectura y Urbanismo.

\section{A Frecuencia de publicación}

Desde 1999 y hasta el 2015, la Revista de Arquitectura (Bogotá) publicó un volumen al año, a partir del 2016 se publicarán dos números por año en periodo anticipado, enero-junio y julio-diciembre, pero también maneja la publicación anticipada en línea de los artículos aceptados (versión Post-print del autor).

La Revista de Arquitectura (Bogotá) se divulga mediante versiones digitales (PDF, HTML, EPUB, XML) e impresascon un tiraje de 700 ejemplares, los tiempos de producción de estas versiones dependerán de los cronogramas establecidos por la editorial.

Los tiempos de recepción-revisión-aceptación pueden tardar entre seis y doce meses dependiendo del flujo editorial de cada sección y del proceso de revisión y edición adelantado.

Con el usuario y contraseña asignados, los autores pueden ingresar a la plataforma de gestión editorial y verificar el estado de revisión, edición o publicación del artículo.
A Canje

La Revista de Arquitectura (Bogotá) está interesada en establecer canje con publicaciones académicas, profesionales o científicas del área de Arquitectura y Urbanismo, como medio de reconocimiento y discusión de la producción científica en el campo de acción de la publicación.

\section{Mecanismo}

Para establecer canje por favor descargar, diligenciar y enviar el formato: RevArq FP20 Canjes

\section{Universidad Católica de Colombia (2019, enero-junio). Revista de Arquitectura (Bogotá), $2 I(\mathrm{I})$ I-120. Doi: 10.14718 \\ ISSN: 1657-0308 E-ISSN: 2357-626X \\ Especificaciones: Formato: $34 \times 24 \mathrm{~cm}$ Papel: Mate $115 \mathrm{~g}$ Tintas: Negro y policromía}

A Contacto

Dirección postal:

Avenida Caracas No. 46-72.

Universidad Católica de Colombia

Bogotá D.C.(Colombia)

Código postal: 111311

Facultad de Diseño

Centro de Investigaciones (CIFAR).

Sede El Claustro. Bloque "L", 4 piso

Diag. 46a No. $15 b-10$

Editor, Arq. César Eligio-Triana

Teléfonos:

+57 (1) $3277300-3277333$

Ext. $3109 ; 3112$ o 5146

Fax: +57 (1) 2858895
Correo electrónico:

revistadearquitectura@ucatolica.edu.co

cifar@ucatolica.edu.co

Página WEB:

www.ucatolica edu.co

vínculo Revistas científicas

http://publicaciones.ucatolica.edu.co revistas-cientificas

http://editorial.ucatolica.edu.co/ojsucatolica/revistas_ucatolica/index.php/RevArq 
Universidad Católica de Colombia

Presidente

Édgar Gómez Betancourt

Vicepresidente - Rector

Francisco José Gómez Ortiz

Vicerrector Jurídico

Edwin de Jesús Horta Vásquez

Vicerrector Administrativo

Édgar Gómez Ortiz

Vicerrector Académico

Elvers Medellín Lozano

Vicerrector de Talento Humano

Ricardo López Blum

Director de Investigaciones

Edwin Daniel Durán Gaviria

Directora Editorial

Stella Valbuena García

\section{Facultad de Diseño}

Decano

Werner Gómez Benítez

Director de docencia

Jorge Gutiérrez Martínez

Directora de extensión

Mayerly Rosa Villar Lozano

Director de investigación

Hernando Verdugo Reyes

Director de gestión de calidad

Augusto Forero La Rotta

Comité asesor externo

Facultad de Diseño

Édgar Camacho Camacho

Martha Luz Salcedo Barrera

Samuel Ricardo Vélez
Facultad de Diseño

Centro de Investigaciones - CIFAR

\section{REVISTA DE ARQUITECTURA \\ Revista de Arquitectura \\ (Bogotá)}

Revista de acceso abierto,

arbitrada e indexada

Publindex: Categoría B. Índice Bibliográfico Nacional IBN.

Esci: Emerging Source Citation Index.

Doaj: Directory of Open Access Journals.

Redalyc: Red de Revistas Cientificas de América Latina y el Caribe,

España y Portugal.

SciELO: Scientific Electronic Library Online - Colombia

Redib: Red Iberoamericana de Innovación y Conocimiento Cientifico.

Ebsco: EBSCOhost Research Databases.

Clase: Base de datos bibliográfica de revistas de ciencias sociales y

humanidades.

Latindex: Sistema Regional de Información en Línea para Revistas

Científicas de América Latina, el Caribe, España y Portugal (Directorio

y catálogo).

Dialnet: Fundación Dialnet - Biblioteca de la Universidad de La Rioja.

LatinRev: Red Latinoamericana de Revistas Académicas en Ciencias

Sociales $y$ Humanidades.

Proquest: ProQuest Research Library.

Miar: Matrix for the Analysis of Journals.

Sapiens Research: Ranking de las mejores revistas colombianas según

visibilidad internacional.

Actualidad Iberoamericana: (Índice de Revistas) Centro de Información

Tecnológica (CIT).

Google Scholar

Arla: Asociación de Revistas latinoamericanas de Arquitectura.

\section{Editorial}

Av. Caracas № 46-72, piso 5

Teléfono: 3277300 Ext. 5145

editorial@ucatolica.edu.co

www.ucatolica.edu.co

http://publicaciones.ucatolica.edu.co)

Impresión:

JaVEGRAF

Calle 46A No82-54 Int. 2

Bogotá, D. C., Colombia

http://www.javegraf.com.co/index.php

Enero de 2019
Director

Werner Gómez Benítez

Editor

César Eligio-Triana

Editores de sección

(1) Myriam Stella Díaz-Osorio

(1) Carolina Rodríguez-Ahumada

(4) Anna Maria Cereghino-Fedrigo

\section{Equipo editorial}

Coordinadora editorial

María Paula Godoy Casasbuenas

mpgodoy@ucatolica.edu.co

Diseño y montaje

Juanita Isaza

juanaisaza@gmail.com

Traductoras

Inglés

Erika Tanacs

etanacs25@gmail.com

Portugués

Roanita Dalpiaz

roanitad@gmail.com

Correctora de estilo

María José Díaz Granados M.

mariajose_dgm@yahoo.com.co

Página Web

Centro de investigaciones (CIFAR)

Distribución y canjes

Claudia Álvarez Duquino

calvarez@ucatolica.edu.co
Comité editorial y científico

Cultura y espacio urbano

Carlos Mario Yory, PhD

Universidad Católica de Colombia. Bogotá, Colombia

Sonia Berjman, $\mathrm{PhD}$

ICOMOS-IFLA, Buenos Aires, Argentina

Juan Carlos Pérgolis, MSc Universidad Piloto de Colombia. Bogotá, Colombia

Beatriz García Moreno, PhD

Universidad Nacional de Colombia. Bogotá, Colombia

Proyecto arquitectónico y urbano

Jean-Philippe Garric, PhD, HDR

Université Paris I Panthéon-Sorbonne. Paris, Francia

Debora Domingo Calabuig, PhD

Universidad Politécnica de Valencia, España

Dania González Couret, PhD

Universidad Tecnológica de La Habana, Cuba

Hugo Mondragón López, PhD Pontificia Universidad Católica de Chile. Santiago, Chile

Juan Pablo Duque Cañas, PhD

Universidad Nacional de Colombia. Bogotá, Colombia

Tecnología, medioambiente y sostenibilidad

Mariano Vázquez Espí, PhD

Universidad Politécnica de Madrid, España

Denise Helena Silva Duarte, PhD Universidade de São Paulo (USP), Brasil

Luis Carlos Herrera Sosa, PhD Universidad Autónoma de Ciudad Juárez, México

Claudio Varini, PhD

Universidad Católica de Colombia. Bogotá, Colombia

Luis Gabriel Gómez Azpeitia, PhD Universidad de Colima. Colima, México 


\section{CONTENIDO}
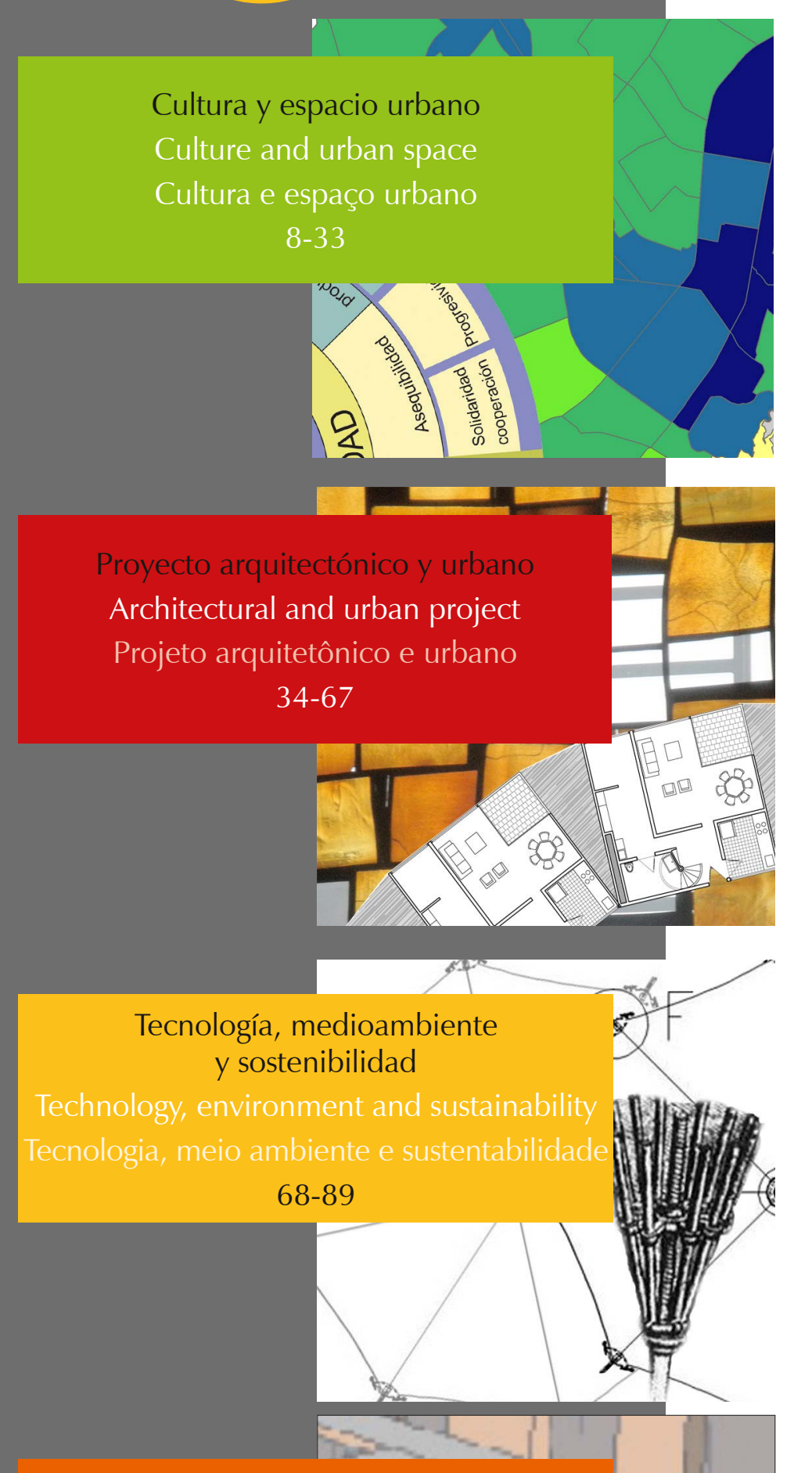

Desde la Facultad

From the Faculty

Da faculdade

90-109

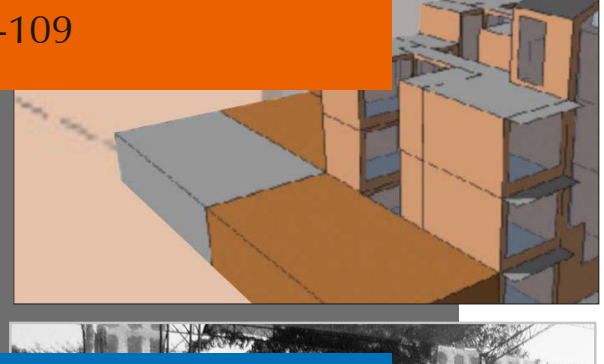

Textos

Texts

Textos

110-118
Revistas en tiempos tecno-humanos

Julio Arroyo

Pág. 3

ES

Índice de caminabilidad para la ciudad de Bogotá

Julián Alberto Gutiérrez-López
Yolanda Beatriz Caballero-Pérez
Rubén Alejandro Escamilla-Triana

ES

Pág. 8

Principios, criterios y propósitos de desarrollo sustentable para la redensificación en contextos urbanos informales
Juan José Castiblanco-Prieto
Fabián Adolfo Aguilera-Martínez
Fabián Alonso Sarmiento-Valdés

Pág. 21

ES

Complejidad y constructivismo en la nueva tradición de la arquitectura de la posguerra

Francisco Javier Fuentes-Farías

Pág. 34 ES

Conservación del arte contemporáneo

El caso de Mathias Goeritz en la Catedral

Metropolitana de México

Alberto Cedeño-Valdiviezo

Pablo Torres-Lima

Pág. 44

\section{ES EN}

Operando desde la forma: un procedimiento

para la valoración de la vivienda colectiva

Julián Camilo Valderrama-Vidal

Pág. 54

ES

Disponibilidad de las técnicas constructivas

de habitación en madera, en Brasil

Victor A. De Araujo

Carlos M. Gutiérrez-Aguilar

Juliana Cortez-Barbosa

Maristela Gava

José N. Garcia

Pág. 68

ES

Diseño y construcción de un paraguas plegable para espacios arquitectónicos

Carlos César Morales-Guzmán

Pág. 76

ES EN

Envolventes eficientes

Relación entre condiciones ambientales, espacios confortables

y simulaciones digitales

Natalia Medina-Patrón

Jonathan Escobar-Saiz

Pág. 90

ES

(Re)pensando el enfoque tecnológico:

el caso del Centro Experimental de la Vivienda

Económica (CEVE) en Argentina

Gustavo Pelegrin

Laila Fleker

Aurelio Ferrero

Pág.110 
La postulación de un artículo a la Revista de Arquitectura (Bogotá) indica que- el o los autores certifican que conocen y aceptan la política editorial, para lo cual firmarán en original y remitirán el formato RevArq FP00 Carta de originalidad.

La Revista de Arquitectura (Bogotá) maneja una política de Autoarchivo VERDE, según las directrices de SHERPA/RoMEO, por lo cual el autor puede:

- Pre-print del autor: Archivar la versión pre-print (la versión previa a la revisión por pares

- Post-print del autor: Archivar la versión post-print (la versión final posterior a la revisión por pares

- Versión de editor/PDF: Archivar la versión del editor - PDF/HTML/XLM en la maqueta de la Revista de Arquitectura (Bogotá).

El Autoarchivo se debe hacer respetando la licencia de acceso abierto, la integridad y la imagen de la Revista de Arquitectura (Bogotá), también se recomienda incluir la referencia, el vínculo electrónico y el DOI.

El autor o los autores son los titulares del Copyright (c) del texto publicado y la Editorial de la Revista de Arquitectura (Bogotá) solicita la firma de una autorización de reproducción del artículo (RevArq FP03 Autorización reproducción), la cual se acoge a la licencia CC, donde se expresa el derecho de primera publicación de la obra.

La Revista de Arquitectura (Bogotá) se guía por las normas internacionales sobre propiedad intelectual y derechos de autor, y de manera particular el artículo 58 de la Constitución Política de Colombia, la Ley 23 de 1982 y el Acuerdo 172 del 30 de septiembre de 2010 (Reglamento de propiedad intelectual de la Universidad Católica de Colombia)

Para efectos de autoría y coautoría de artículos se diferencian dos tipos: "obra en colaboración" y "obra colectiva". La primera es aquella cuya autoría corresponde a todos los participantes al ser fruto de su trabajo conjunto. En este caso, quien actúa como responsable y persona de contacto debe asegurar que quienes firman como autores han revisado y aprobado la versión final, y dan consentimiento para su divulgación. La obra colectiva es aquella en la que, aunque participan diversos colaboradores, hay un autor que toma la iniciativa la coordinación y realización de dicha obra. En estos casos, la autoría corresponderá a dicha persona (salvo pacto en contrario) y será suficiente únicamente con su autorización de divulgación.

El número de autores por artículo debe estar justificado por el tema, la complejidad y la extensión, y no deberá ser superior a la media de la disciplina, por lo cual se recomienda que no sea mayor de cinco. El orden en que se enuncien corresponderá a los aportes de cada uno a la construcción del texto, se debe evitar la autoría ficticia o regalada. Si se incluyen más personas que trabajaron en la investigación se sugiere que sea en calidad de colaboradores o como parte de los agradecimientos. La Revista de Arquitectura (Bogotá) respetará el número y el orden en que figuren en el original remitido. Si los autores consideran necesario, al final del artículo pueden incluir una breve descripción de los aportes individuales de cada uno de firmantes.

La comunicación se establece con uno de los autores, quien a su vez será el responsable de informar a los demás autores de las notificaciones emitidas por la Revista de Arquitectura (Bogotá).

En virtud de mantener el equilibro de las secciones y las mismas oportunidades para todos los participantes, un mismo autor puede postular dos o más artículos de manera simultánea; si la decisión editorial es favorable y los artículos son aceptados, su publicación se realizará en números diferentes.

\section{A Acceso abierto}

La Revista de Arquitectura (Bogotá), en su misión de divulgar la investigación y apoyar el conocimiento y la discusión en los campos de interés, proporciona acceso abierto, inmediato e irrestricto a su contenido de manera gratuita mediante la distribución de ejemplares impresos y digitales. Los interesados pueden leer, descargar, guardar, copiar y distribuir, imprimir, usar, buscar o referenciar el texto completo o parcial de los artículos o la totalidad de la Revista de Arquitectura (Bogotá).

\section{(c) (1) (3)}

Esta revista se acoge a la licencia Creative Commons (CC BY NC de Atribución - No comercial 4.0 Internacional): "Esta licencia permite a otros entremezclar, ajustar y construir a partir de su obra con fines no comerciales, y aunque en sus nuevas creaciones deban reconocerle su autoría y no puedan ser utilizadas de manera comercial, no tienen que estar bajo una licencia con los mismos términos".

La Revista de Arquitectura es divulgada en centros y grupos de investigación, en bibliotecas y universidades, y en las principales facultades de Arquitectura mediante acceso abierto a la versión digital y suscripción anual al ejemplar impreso o por medio de canje, este último se formaliza mediante el formato RevArq FP20 Canjes

Para aumentar su visibilidad y el impacto de los artículos, se envían a bases de datos y sistemas de indexación y resumen (SIR) y, asimismo, pueden ser consultados y descargados en la página web de la revista.

La Revista de Arquitectura no maneja cobros, tarifas o tasas de publicación de artículo (Article Processing Charge-APC), o por el sometimiento de textos a la publicación.

\section{(A) Ética y buenas prácticas}

La Revista de Arquitectura se compromete a cumplir y respetar las normas éticas en todas las etapas del proceso de publicación. Los autores de los artículos publicados darán cumplimiento a los principios éticos contenidos en las diferentes declaraciones y legislaciones sobre propiedad intelectual y derechos de autor específicos del país donde se realizó la investigación. En consecuencia, los autores de los artículos postulados y aceptados para publicar, que presentan resultados de investigación, deben firmar la declaración de originalidad (formato RevArq FP00 Carta de originalidad).

La Revista de Arquitectura reconoce y adopta los principios de transparencia y buenas prácticas descritos por COPE, "Principles of Transparency and Best Practice in Scholarly Publishing" (2015).

El equipo editorial tiene la obligación de guardar la confidencialidad acerca de los artículos recibidos, y abstenerse de usar en sus propias investigaciones datos, argumentos o interpretaciones hasta tanto el artículo no sea publicado. También debe ser imparcial y gestionar los artículos de manera adecuada y en los plazos establecidos. La selección de revisores se hará con objetividad y estos deberán responder a la temática del artículo.

El editor, los autores y los revisores deben seguir las normas éticas internacionales definidas por el Committee on Publication Ethics (COPE), con el fin de evitar casos de:

- Fabricación, falsificación u omisión de datos.

- Plagio y autoplagio.

- Publicación redundante, duplicada o fragmentada.

- Omisión de referencias a las fuentes consultadas.

- Utilización de contenidos sin permiso o sin justificación.

- Apropiación individual de autoría colectiva.

- Cambios de autoría.

- Conflicto de interés (CDI) no revelado o declarado.

- Otras que pudieran surgir en el proceso de investigación y publicación. La fabricación de resultados se genera al mostrar datos inventados por los autores; la falsificación resulta cuando los datos son manipulados y cambiados a capricho de los autores; la omisión se origina cuando los autores ocultan deliberadamente un hecho o dato. El plagio se da cuando un autor presenta como ideas propias datos creados por otros. Los casos de plagio son los siguientes: copia directa de un texto sin entrecomillar o citar la fuente, modificación de algunas palabras del texto, paráfrasis y falta de agradecimientos; el autoplagio se da cuando el mismo autor reutiliza material propio que ya fue publicado, pero sin indicar la referencia al trabajo anterior. La revista se apoya en herramientas digitales que detectan cualquiera de estos casos en los artículos postulados, y es labor de los editores y revisores velar por la originalidad y fidelidad en la citación. La publicación redundante o duplicada se refiere a la copia total, parcial o alterada de un trabajo ya publicado por el mismo autor

En caso de sospechar de alguna mala conducta se recomienda seguir los diagramas de flujo elaborados por COPE (2008), con el fin de determinar las acciones correspondientes.

La Revista de Arquitectura se reserva el derecho de retractación de publicación de aquellos artículos que, posterior a su publicación, se demuestre que presentan errores de buena fe, o cometieron fraudes o malas prácticas científicas. Esta decisión se apoyará en "Retraction Guidelines" (COPE, 2009). Si el error es menor, este se podrá rectificar mediante una nota editorial de corrección o una fe de erratas. Los autores también tienen la posibilidad de solicitar la retractación de publicación cuando descubran que su trabajo presenta errores graves. En todos los casos se conservará la versión electrónica y se harán las advertencias de forma clara e inequívoca.

\section{A Privacidad y manejo de la información.} Habeas Data

Para dar cumplimiento a lo previsto en el artículo 10 del Decreto 1377 de 2013, reglamentario de la Ley 1581 de 2012, y según el Acuerdo 002 del 4 de septiembre de 2013 de la Universidad Católica de Colombia, "por el cual se aprueba el manual de políticas de tratamiento de datos personales":

La Universidad Católica de Colombia, considerada como responsable o encargada del tratamiento de datos personales, manifiesta que los datos personales de los autores, integrantes de los comités y pares revisores, se encuentran incluidos en nuestras bases de datos; por lo anterior, y en cumplimiento de las disposiciones legales vigentes, la Universidad solicitará siempre su autorización, para que en desarrollo de sus funciones propias como Institución de Educación Superior, en especial las relacionadas con la docencia, la extensión y la investigación, la Universidad Católica de Colombia pueda recolectar, recaudar, almacenar, usar, circular, suprimir, procesar, intercambiar, compilar, dar tratamiento, actualizar, transmitir o transferir a terceros países y disponer de los datos que le han suministrado y que han sido incorporados en las bases de datos de todo tipo que reposan en la Universidad.

La Universidad Católica de Colombia queda autorizada, de manera expresa e inequívoca, en los términos señalados por el Decreto 1377 de 2013, para mantener y manejar la información de nuestros colaboradores (autores, integrantes de los diferentes comités y pares revisores); así mismo, los colaboradores podrán ejercer sus derechos a conocer, actualizar, rectificar y suprimir sus datos personales, para lo cual se han dispuesto las siguientes cuentas de correo electrónico: 
La Revista de Arquitectura (Bogotá) recibe artículos de manera permanente. Los artículos se procesan a medida que se postulan, dependiendo el flujo editorial de cada sección.

El idioma principal es el español, y como opcionales están definidos el inglés, el portugués y el francés; los textos pueden ser escritos y presentados en cualquiera de estos.

Los artículos postulados deben corresponder a las categorías universalmente aceptadas como producto de investigación, ser originales e inéditos y sus contenidos responder a criterios de precisión, claridad y brevedad.

Como punto de referencia se pueden tomar las tipologías y definiciones del Îndice Bibliográfico Nacional, Publindex (2010) que se describen la continuación:

1. Artículo de revisión: documento resultado de una investigación terminada donde se analizan, sistematizan e integran los resultados de investigaciones publicadas o no publicadas, sobre un campo en ciencia o tecnología, con el fin de dar cuenta de los avances y las tendencias de desarrollo. Se caracteriza por presentar una cuidadosa revisión bibliográfica de por lo menos 50 referencias.
2. Artículo de investigación científica y tecnológica: documento que presenta, de manera detallada, los resultados originales de proyectos terminados de investigación. La estructura generalmente utilizada contiene cuatro apartes importantes: introducción, metodología, resultados y conclusiones.

3. Artículo de reflexión: documento que presenta resultados de investigación terminada desde una perspectiva analítica, interpretativa o crítica del autor, sobre un tema específico, recurriendo a fuentes originales.

Adicional a estas tipologías, se pueden presentar otro tipo de artículos asociados a procesos de investigación-creación y/o investigación proyectual. En todos los casos se debe presentar la información suficiente para que cualquier investigador pueda reproducir la investigación y confirmar o refutar las interpretaciones defendidas y sea evidente el aporte a la disciplina.

En todos los casos se debe presentar la información suficiente para que cualquier investigador pueda reproducir la investigación y confirmar o refutar las interpretaciones defendidas.

\section{(A) Instrucciones para postular artículos}

Postular el artículo en la página web de la Revista de Arquitectura (Bogotá) y adjuntar comunicación escrita dirigida al editor RevArq_FP00 Carta de originalidad (debidamente firmada por todos los autores en original); de igual manera, se debe diligenciar el formato de hoja de vida RevArq FP01 Hoja de Vida (una por cada autor).

En la comunicación escrita el autor expresa que conoce y acepta la política editorial de la Revista de Arquitectura (Bogotá), que el artículo no está postulado para publicación simultáneamente en otras revistas u órganos editoriales y que no existe conflicto de intereses (ver modelo RevArq FP06 CDI) y que, de ser aceptado, concederá permiso de primera publicación, no exclusiva a nombre de la Universidad Católica de Colombia como editora de la revista.

Los artículos deben tener en cuenta las siguientes recomendaciones:

- En la primera página del documento se debe incluir:

Tírulo: no exceder 15 palabras

Subtítulo: opcional, complementa el título o indica las principales subdivisiones del texto.

Nombre del autor o autores: nombres y apellidos completos o según modelo de citación adoptado por el autor para la normalización de los nombres del investigador. Como nota al pie (máximo 100 palabras) formación académica, experiencia profesional e investigativa, código ORCID https://orcid.org/, e información de contacto, correo electrónico.

Filiación institucional: debajo del nombre se debe declarar la ins-titución en la cual se desarrolló el producto, de la cual recibió apoyo o aquella que respalda el trabajo investigativo.

Resumen: debe ser analítico, se redacta en un solo párrafo, da cuenta del tema, el objetivo, la metodología, los resultados y las conclusiones; no debe exceder las 150 palabras.

Palabras clave: cinco palabras o grupo de palabras, ordenadas alfabéticamente y que no se encuentren en el título o subtítulo; estas sirven para clasificar temáticamente al artículo. Se recomienda emplear principalmente palabras definidas en el tesauro de la Unesco (http://databases. unesco.org/thessp/), en el tesauro de Arte \& Arquitectura (C) (www.aatespanol.cl), o Vitruvio (http://vocabularyserver.com/vitruvio/)

También se recomienda incluir título, resumen y palabras clave en segundo idioma.

- La segunda página y siguientes deben tener en cuenta:

El cuerpo del artículo se divide en: Introducción, Metodología, Resultados y Discusión de resultados; posteriormente se presentan las Conclusiones, y luego las Referencias bibliográficas y los Anexos (modelo IMRYD). Las tablas y figuras se deben incorporar en el texto.

Descripción del proyecto de investigación: en la introducción se debe describir el tipo de artículo y brevemente el marco investigativo del cual es resultado y diligenciar el formato (RevArq FP02 Info Proyectos de Investigación).

TEXTO: todas las páginas deben venir numeradas y con el título de artículo en la parte superior de la página. Márgenes de $3 \mathrm{~cm}$ por todos los lados, interlineado doble, fuente Arial o Times New Roman de 12 puntos, texto justificado (Ver plantilla para presentación de artículos). La extensión de los artículos debe ser de alrededor de 5.000 palabras ( \pm 20 páginas, incluyendo gráficos, tablas, referencias, etc.); como mínimo 3.500 y máximo 8.000 palabras. Se debe seguir el estilo vigente y recomendado en el Manual para Publicación de la American Psychological Association (APA). (Para mayor información véase http://www.apastyle.org/)
Citas y notas al pie: las notas aclaratorias o notas al pie no deben exceder cinco líneas o 40 palabras, de lo contrario estas deben ser incorporadas al texto general. Las citas pueden ser:

Corta: (con menos de 40 palabras) se incorporan al texto y pueden ser: textuales (se encierran entre dobles comillas), parafraseo o resumen (se escriben en palabras del autor dentro del texto).

Cita textual extensa: (mayor de 40 palabras) debe ser dispuesta en un renglón y un bloque independiente con sangrías y omitiendo las comillas, no olvidar en ningún caso la referencia del autor (Apellido, año, página).

Referencias: como modelo para la construcción de referencias se emplea el estilo recomendado en el Manual para Publicación de la American Psychological Association (APA) (http://www.apastyle.org/).

Siglas: en caso de emplear siglas en el texto, las figuras o las tablas, se debe proporcionar la equivalencia completa la primera vez que se empleen y encerrarlas entre paréntesis. En el caso de citar personajes reconocidos se deben colocar nombres o apellidos completos, nunca emplear abreviaturas.

Figuras y tablas: las figuras (gráficos, diagramas, ilustraciones, planos, mapas o fotografías) y las tablas deben ir numeradas y contener título o leyenda explicativa relacionada con el tema del artículo, que no exceda las 15 palabras (Figura 1. xxxxx, Tabla 1. xxxx, etc.) y la procedencia (fuente: autor o fuente, año, página). Estas se deben referenciar en el texto de forma directa o entre paréntesis; se recomienda hacerlo con referencias cruzadas.

También se deben entregar en medio digital, independiente del texto, en formatos editables o abiertos. La marcación de los archivos debe corresponder a la incluida en el texto. Según la extensión del artículo se deben incluir de 5 a 10 gráficos. Ver guía para la búsqueda de imágenes de dominio público o bajo licencias Creative Commons (CC).

El autor es el responsable de adquirir los derechos o las autorizaciones de reproducción a que haya lugar para imágenes o gráficos tomados de otras fuentes, así como de entrevistas o material generado por colaboradores diferentes a los autores; de igual manera, se debe garantizar la protección de datos e identidades para los casos que sea necesario.

FotografíA: pueden ser entregadas en original para ser digitalizadas, de lo contrario se deben digitalizar con una resolución igual o superior a 300 dpi para imágenes a color y 600 para escala de grises. Los formatos de las imágenes pueden ser TIFF, PSD o JPG, y deben cumplir con las características expresadas en el punto anterior (figuras).

Planimetría: se debe entregar la planimetría original en medio digital, en lo posible en formato CAD, y sus respectivos archivos de plumas o en PDF; de no ser posible, se deben hacer impresiones en tamaño carta con las referencias de los espacios mediante numeración y lista adjunta. Deben tener escala gráfica, escala numérica, norte, coordenadas y localización. En lo posible, no deben contener textos, achurados o tramas.

Para más detalles, consultar el documento RevArq Parámetros para Autores Descripción en el portal web de la Revista de Arquitectura (Bogotá)

\section{Beneficios}

Como reconocimiento a los autores, se les hará envío postal de dos ejemplares de la edición impresa sin ningún costo y entregada en la dirección consignada en el formato de hoja de vida (RevArq FP01); adicionalmente, se enviará el vínculo para la descarga de la versión digital.

También se enviará una constancia informativa en la que se relaciona la publicación del artículo y, de manera opcional, se pueden detallar las fechas del proceso editorial y el arbitraje realizado. 
La selección de revisores se realiza de acuerdo con los siguientes criterios:

- Afinidad temática.

- Formación académica.

- Experiencia investigativa y profesional.

- Producción editorial en revistas similares o en libros resultado de investigación.

El proceso de arbitraje se basa en los principios de equidad e imparcialidad, y en los criterios de calidad y pertinencia.

El desarrollo de la revisión se realiza según el formato (RevArq FP10 Evaluación de artículos) y las observaciones que el revisor considere necesarias en el cuerpo del artículo. En cualquiera de los conceptos que emita el revisor (Aceptar, Publicable con modificaciones, Reevaluable o No publicable), y como parte de la labor formativa y de comunidad académica, el revisor hará sugerencias para mejorar et documento. El revisor podrá solicitar una nueva relectura del artículo después de los ajustes realizados por el autor.

El revisor también deberá diligenciar el formato RevArq FP01 Hoja de Vida, con el fin de certificar y soportar el proceso de revisión ante los SIR que así lo soliciten.

En el proceso de arbitraje se emplea el método doble ciego, los nombres del revisor no serán conocidos por el autor y viceversa. Con el fin de garantizar el anonimato del autor, al artículo postulado se le han podido suprimir nombres, instituciones o imágenes que puedan ser asociadas de manera directa al autor.

Aunque se procura el anonimato, una vez recibida la invitación como par revisor del artículo, el revisor debe cerciorarse de que no exista conflicto de intereses (CDI) o alguna limitante que afecte la revisión o que pueda ser vista como tal (lazos familiares, amistad o enemistad, vínculos contractuales o laborales, posiciones éticas, etc.), de presentarse esta situación se notificara al editor. (Ver modelo RevArq FP06 CDI).

Dada la confidencialidad del proceso de revisión, y considerando los derechos de autor y de propiedad intelectual que pueda haber sobre el material que se entrega, el revisor se compromete a mantener en absoluta reserva su labor, a limitar el uso de la obra entregada solo para el propósito designado y a devolver la documentación remitida una vez concluya la actividad.

El tiempo establecido para las revisiones de pares es de máximo un mes a partir de la confirmación de la recepción de la documentación. Ese plazo podrá ser modificado de mutuo acuerdo entre e editor y el revisor, siempre y cuando no afecte la periodicidad de la revista, la impresión o el tiempo para emitir una respuesta al autor.

Los revisores se acogerán a "COPE Ethical Guidelines for Peer Reviewers" de COPE.

\section{Beneficios}

Como retribución a los revisores se les hará envío postal de un ejemplar de la edición impresa sin ningún costo y entregada en la dirección consignada en el formato de hoja de vida. También, si es de interés para el revisor, podrá hacer la solicitud de alguna de las publicaciones editadas y presentes en el catálogo de publicaciones de la UNIVERSIDAD CATÓLICA DE COLOMBIA, previa aprobación de la Editorial y sujeto a la disponibilidad.

Si lo desea tendrá derecho a una constancia de la colaboración en la revisión de artículos, la cual solo contendrá el periodo en el cual se realizó la actividad. También tendrá la posibilidad de aceptar o no la publicación de su nombre, nacionalidad y nivel máximo de formación en la página web de la Revista de Arquitectura (Bogotá) en su calidad de colaborador.

\section{A Proceso de revisión por pares}

Luego de la postulación del artículo, el editor de la Revista de Arquitectura (Bogotá) selecciona y clasifica los artículos que cumplen con los requisitos establecidos en las directrices para los autores. El editor podrá rechazar en primera instancia artículos, sin recurrir a un proceso de revisión, si los considera de baja calidad o por presentar evidencias de faltas éticas o documentación incompleta.

Los artículos se someterán a un primer dictamen del editor, de los editores de sección y del Comité Editorial, teniendo en cuenta:

- Afinidad temática, relevancia del tema y correspondencia con las secciones definidas.

- Respaldo investigativo.

- Coherencia en el desarrollo del artículo, así como una correcta redacción y ortografía.

- Relación entre las figuras y tablas con el texto del artículo.
En esta revisión se verificará el nivel de originalidad mediante el uso de software especializado (Ithenticate o similar) y recursos digitales existentes para tal fin, también se observará la coherencia y claridad en los apartados del documento (modelo IMRYD), la calidad de las fuentes y la adecuada citación, esto quedará consignado en el formato (RevArq FP09 Revisión de artículos); esta información será cargada a la plataforma de gestión editorial y estará a disposición del autor.

En caso de que el artículo requiera ajustes preliminares, será devuelto al autor antes de ser remitido a revisores. En este caso, el autor tendrá veinte días para remitir nuevamente el texto con los ajustes solicitados.

Después de la preselección se asignan mínimo dos revisores especializados, quienes emitirán su concepto utilizando el formato (RevArq FP10 Evaluación de artículos) y las anotaciones que consideren oportunas en el texto; en esta etapa se garantizará la confidencialidad y el anonimato de autores y revisores (modalidad doble ciego).

Del proceso de revisión se emite uno de los siguientes conceptos que será reportado al autor:

\section{- Aceptar el envío: con o sin observaciones.}

- Publicable con modificaciones: se podrá sugerir la forma más adecuada para una nueva presentación, el autor puede o no aceptar las observaciones según sus argumentos. Si las acepta, cuenta con quince días para realizar los ajustes pertinentes.

- Reevaluable: cumple con algunos criterios y debe ser corregido. Es necesario hacer modificaciones puntuales y estructurales al artículo. En este caso, el revisor puede aceptar o rechazar hacer una nueva lectura del artículo luego de ajustado.

- No publicable: el autor puede volver a postular el artículo e iniciar nuevamente el proceso de arbitraje, siempre y cuando se evidencien los ajustes correspondientes.

En el caso de presentarse diferencias sustanciales y contradictorias en los conceptos sobre la recomendación del revisor, el editor remitirá el artículo a un revisor más o a un miembro del Comité Editorial quien podrá actuar como tercer árbitro, con el fin de tomar una decisión editorial sobre la publicación del artículo.

Los autores deberán considerar las observaciones de los revisores o de los editores, y cada corrección incorporada u omitida debe quedar justificada en el texto o en una comunicación adjunta. En el caso que los autores omitan las indicaciones realizadas sin una argumentación adecuada, el artículo será devuelto y no se dará por recibido hasta que no exista claridad al respecto.

El editor respetará la independencia intelectual de los autores y a estos se les brindará el derecho de réplica en caso de que los artículos hayan sido evaluados negativamente y rechazados.

Los autores, con su usuario y contraseña, podrán ingresar a la plataforma de Gestión Editorial, donde encontrarán los conceptos emitidos y la decisición sobre el artículo.

El editor y el Comité Editorial se reservan el derecho de aceptar o no la publicación del material recibido. También se reservan el derecho de sugerir modificaciones de forma, ajustar las palabras clave o el resumen y de realizar la corrección de estilo. El autor conocerá la versión final del texto antes de la publicación oficial del mismo.

Cuando un artículo es aceptado para su publicación, el autor debe firmar la autorización de reproducción (RevArq FP03 Autorización reproducción). Para más información ver: Política de derechos de autor

\section{Notas aclaratorias:}

La Revista de Arquitectura (Bogotá) busca el equilibrio entre las secciones, motivo por el cual, aunque un artículo sea aceptado o continúe en proceso de revisión, podrá quedar aplazado para ser publicado en un próximo número; en este caso, el autor estará en la posibilidad de retirar la postulación del artículo o de incluirlo en el banco de artículos del próximo número.

El editor y los editores de sección de la Revista de Arquitectura (Bogotá) son los encargados de establecer contacto entre los autores y revisores, ya que estos procesos se realizan de manera anónima.
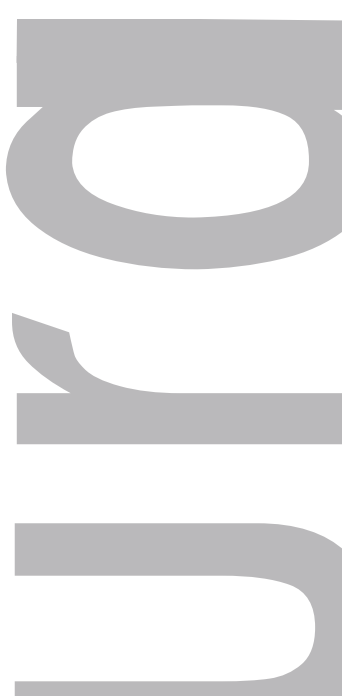
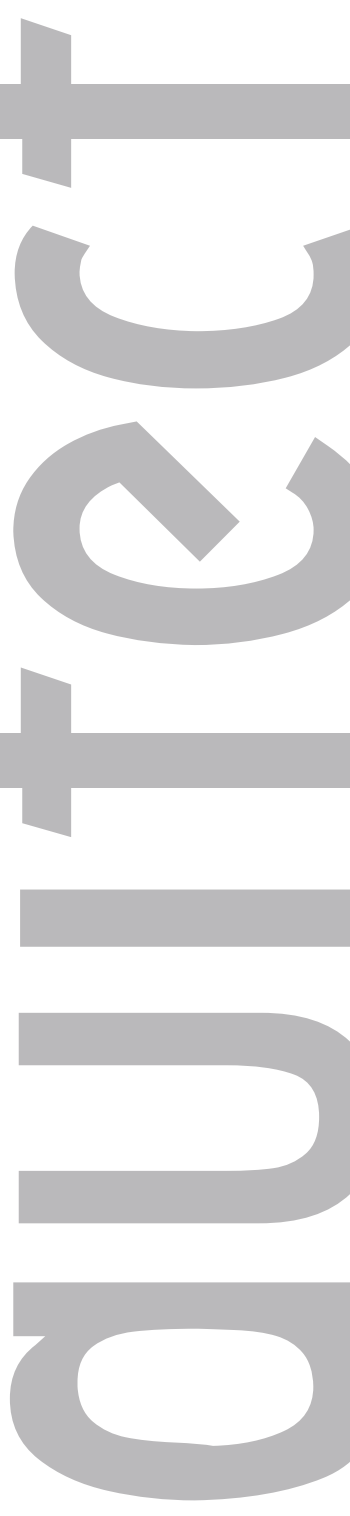

Vol. 


\section{Índice de caminabilidad para la ciudad de Bogotá \\ $\infty \quad$ Walkability index for the city of Bogotá \\ ن Índice de caminhabilidade para a cidade de Bogotá \\ Julián Alberto Gutiérrez-López \\ Yolanda Beatriz Caballero-Pérez
Rubén Alejandro Escamilla-Triana}

Principios, criterios y propósitos de desarrollo sustentable para la $\bar{\Upsilon}$ redensificacion en contextos urbanos informales

Principles, criteria and purposes of sustainable development for

re-densification in unplanned urban context

Princípios, critérios e propósitos de desenvolvimento sustent

Fabián Adolfo Aguilera-Martínez

Fabián Alonso Sarmiento-Valdés

Complejidad y constructivismo en la nueva tradición de la arquitectura de la posguerra

Complexity and constructivism in the new tradition of post-war architecture

U Complexidade e construtivismo na nova tradição da arquitetura do pósguerra

Francisco Javier Fuentes-Farías

Conservación del arte contemporáneo. El caso de Mathias Goeritz en la Catedral Metropolitana de México

Conservation of contemporary art: The case of Mathias Goeritz in the

$\varangle \quad$ Metropolitan Cathedral of Mexico

Conservação da arte contemporânea: o caso de Mathias Goeritz na Catedral Metropolitana do México

\section{Alberto Cedeño-Valdiviezo}

Pablo Torres-Lima

Operando desde la forma: un procedimiento para la valoración de la vivienda colectiva

On Operating based on form: A procedure for the valuation of collective housing

U Operando a partir da forma: um procedimento para avaliar a moradia coletiva

\section{Julián Camilo Valderrama-Vidal}

Disponibilidad de las técnicas constructivas de habitación en

ن Availability of timber housing construction techniques in Brazil

U. Disonibilidade das técnicas construtivas de moradia em madeira no Brasil

\section{Victor A. De Araujo}

Carlos M. Gutiérrez-Aguilar

Juliana Cortez-Barbosa

Maristela Gava

losé N. Garcia

Diseño y construcción de un paraguas plegable

Design and construction of a folding umbrella for architectural spaces

ن Desenho e construção de um guarda-chuva dobrável para espaços arquitetônicos

Carlos César Morales-Guzmán

Envolventes eficientes. Relación entre condiciones ambientales, espacios confortables y simulaciones digitales

(j) Efficient building envelopes: Relationship between environmental conditions,

U. comfortable spaces, and digital simulations

Envolventes eficientes: relação entre condições ambientais, espaços confortáveis e simulações digitais

Natalia Medina-Patrón

Jonathan Escobar-Saiz

(Re)pensando el enfoque tecnológico: el caso del Centro

Experimental de la Vivienda Económica (CEVE) en Argentina

ㅇ $(\mathrm{Re})$ thinking the technological approach: The case of the Experimental Center

으 for Economic Housing (CEVE) in Argentina

ن (Re)pensando a abordagem tecnológica. O caso do Centro Experimental da

Moradia Econômica na Argentina

Gustavo Pelegrin

Laila Fleker

Aurelio Ferrero 